\title{
Modular Synthesis of Arylacetic Acid Esters, Thioesters and Amides from Aryl Ethers via Rh(II)-Catalyzed Diazo Arylation
}

\author{
Daniel Best,* Mickaël Jean, Pierre van de Weghe \\ Université de Rennes 1, UMR CNRS 6226, Institut des Sciences Chimiques de Rennes, \\ Equipe PNSCM, UFR des SciencesBiologiques et Pharmaceutiques, \\ 2 Avenue du Prof Leon Bernard, Rennes F-35043 Cedex, France
}

\section{Supporting Information}

\section{Contents}

1. Screening of ligands and solvents

2. NMR-monitored synthesis of 7a and 7aa

3. NMR spectra for starting materials $\mathbf{1}$ and $\mathbf{2}$

1. Screening of ligands and solvents

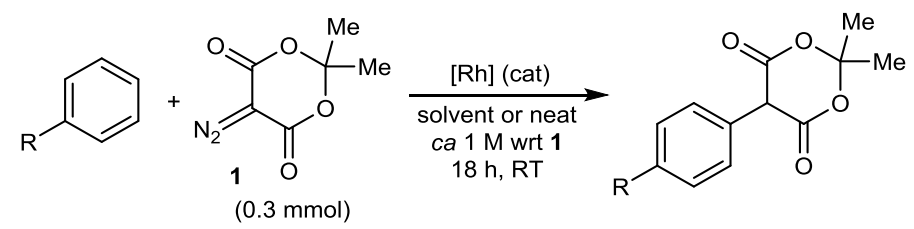

\begin{tabular}{|c|c|c|c|c|}
\hline Entry & Catalyst (mol\%) & $\mathbf{R}$ (equiv) & Solvent & NMR yield \\
\hline 1 & $\mathrm{Rh}_{2}(\mathrm{esp})_{2}(0.7)$ & OMe (10) & - & $>95 \%$ \\
\hline 2 & $\operatorname{Rh}_{2}(\operatorname{esp})_{2}(0.7)$ & Me (10) & - & $65 \%$ \\
\hline 3 & $\mathrm{Rh}_{2}(\mathrm{OPiv})_{4}(1)$ & $\operatorname{Me}(10)$ & - & $45 \%$ \\
\hline 4 & $\mathrm{Rh}_{2}\left(\mathrm{O}_{2} \mathrm{CCPh}_{3}\right)_{4}(1)$ & $\operatorname{Me}(10)$ & - & $35 \%$ \\
\hline 5 & $\mathrm{Rh}_{2}\left(\mathrm{O}_{2} \mathrm{CCF}_{3}\right)_{4}(1)$ & $\operatorname{Me}(10)$ & - & $<5 \%$ \\
\hline 6 & $\mathrm{Rh}_{2}(\mathrm{OAc})_{4}(2)$ & $\mathrm{Me}(10)$ & - & $<5 \%$ \\
\hline 7 & $\operatorname{Rh}_{2}(\operatorname{esp})_{2}(0.7)$ & OMe (2) & 4-chlorobenzotrifluoride & $>95 \%$ \\
\hline 8 & $\mathrm{Rh}_{2}(\mathrm{esp})_{2}(0.7)$ & $\mathrm{OMe}(2)$ & 1-chloro-4-fluorobenzene & $95 \%$ \\
\hline 9 & $\mathrm{Rh}_{2}(\operatorname{esp})_{2}(0.7)$ & OMe (2) & 1-bromo-4-fluorobenzene & $85 \%$ \\
\hline 10 & $\mathrm{Rh}_{2}(\mathrm{esp})_{2}(0.7)$ & OMe (2) & $\mathrm{CH}_{2} \mathrm{Cl}_{2}$ & $80 \%$ \\
\hline 11 & $\mathrm{Rh}_{2}(\mathrm{esp})_{2}(0.7)$ & OMe (2) & $\mathrm{C}_{6} \mathrm{~F}_{6}$ & $<5 \%$ \\
\hline 12 & $\operatorname{Rh}_{2}(\operatorname{esp})_{2}(0.7)$ & Me (2) & 4-chlorobenzotrifluoride & $45 \%$ \\
\hline 13 & $\mathrm{Rh}_{2}(\mathrm{esp})_{2}(0.7)$ & $\mathrm{Me}(2)$ & $\mathrm{CH}_{2} \mathrm{Cl}_{2}$ & $40 \%$ \\
\hline 14 & $\mathrm{Rh}_{2}(\mathrm{esp})_{2}(0.7)$ & $\mathrm{Me}(2)$ & 1,2-dichloroethane & $30 \%$ \\
\hline
\end{tabular}




\section{NMR-monitored synthesis of $7 \mathbf{a}$ and $7 a a$}
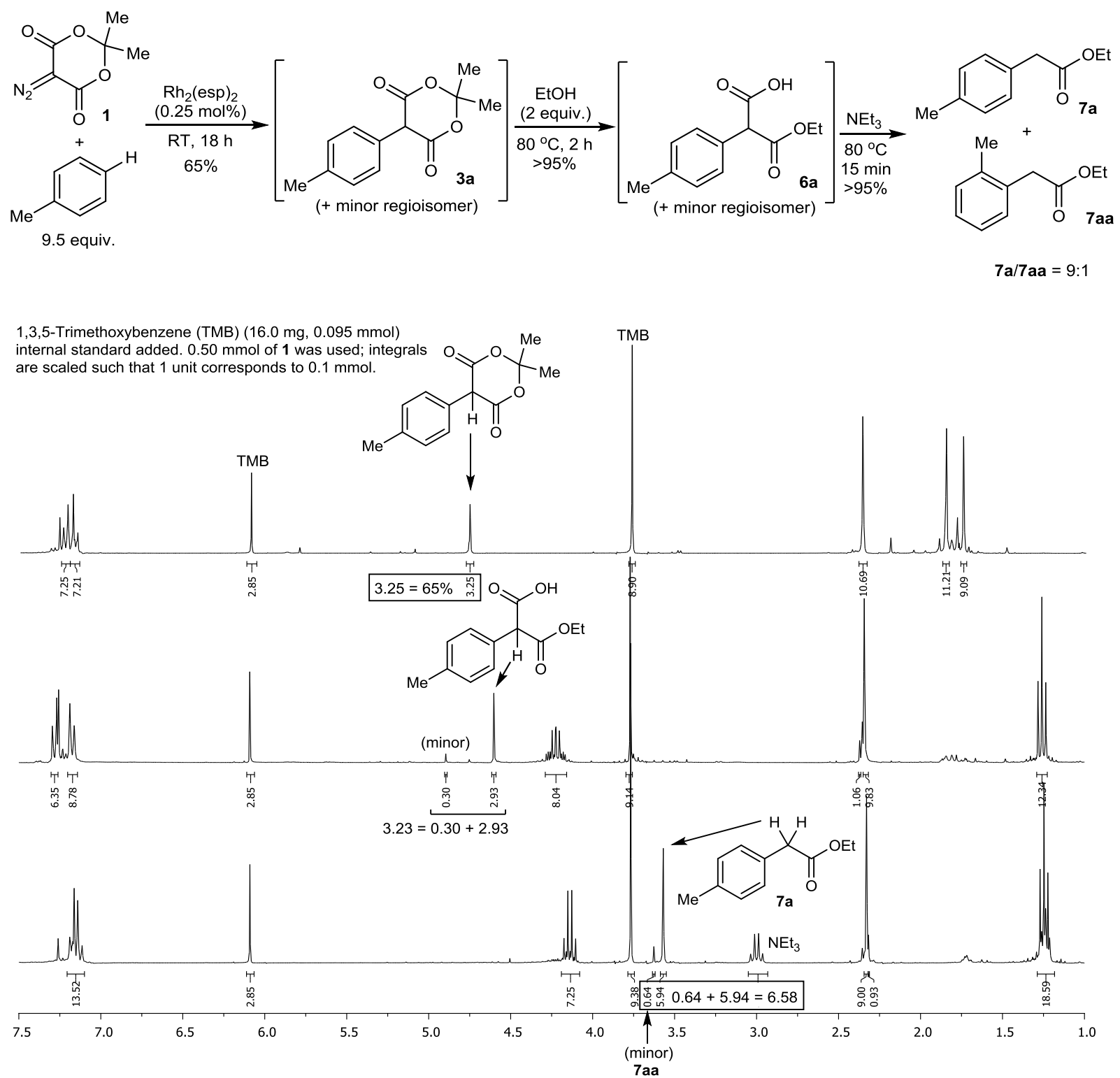
3. NMR spectra for starting materials 1 and 2

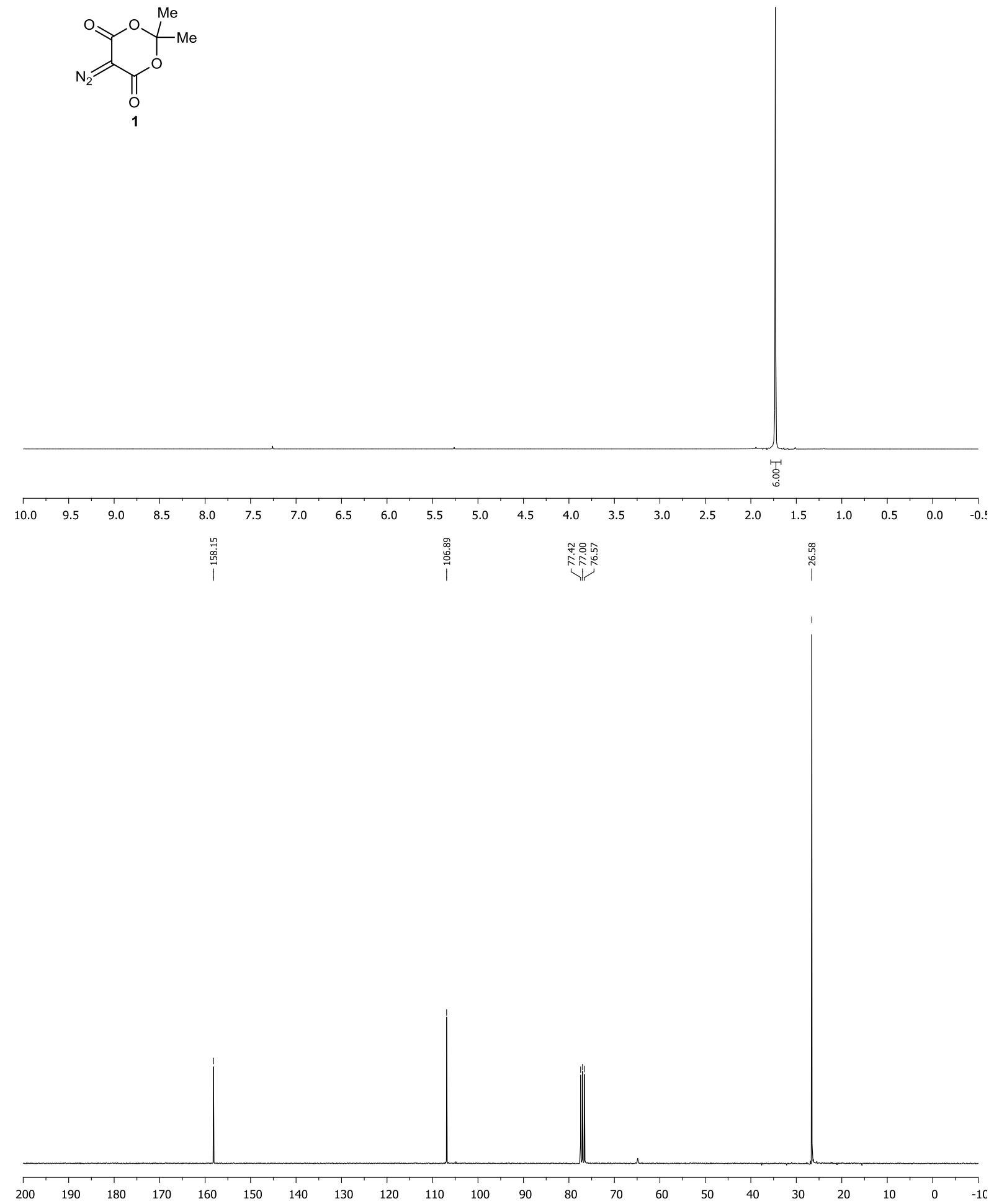


Supporting Information

SH

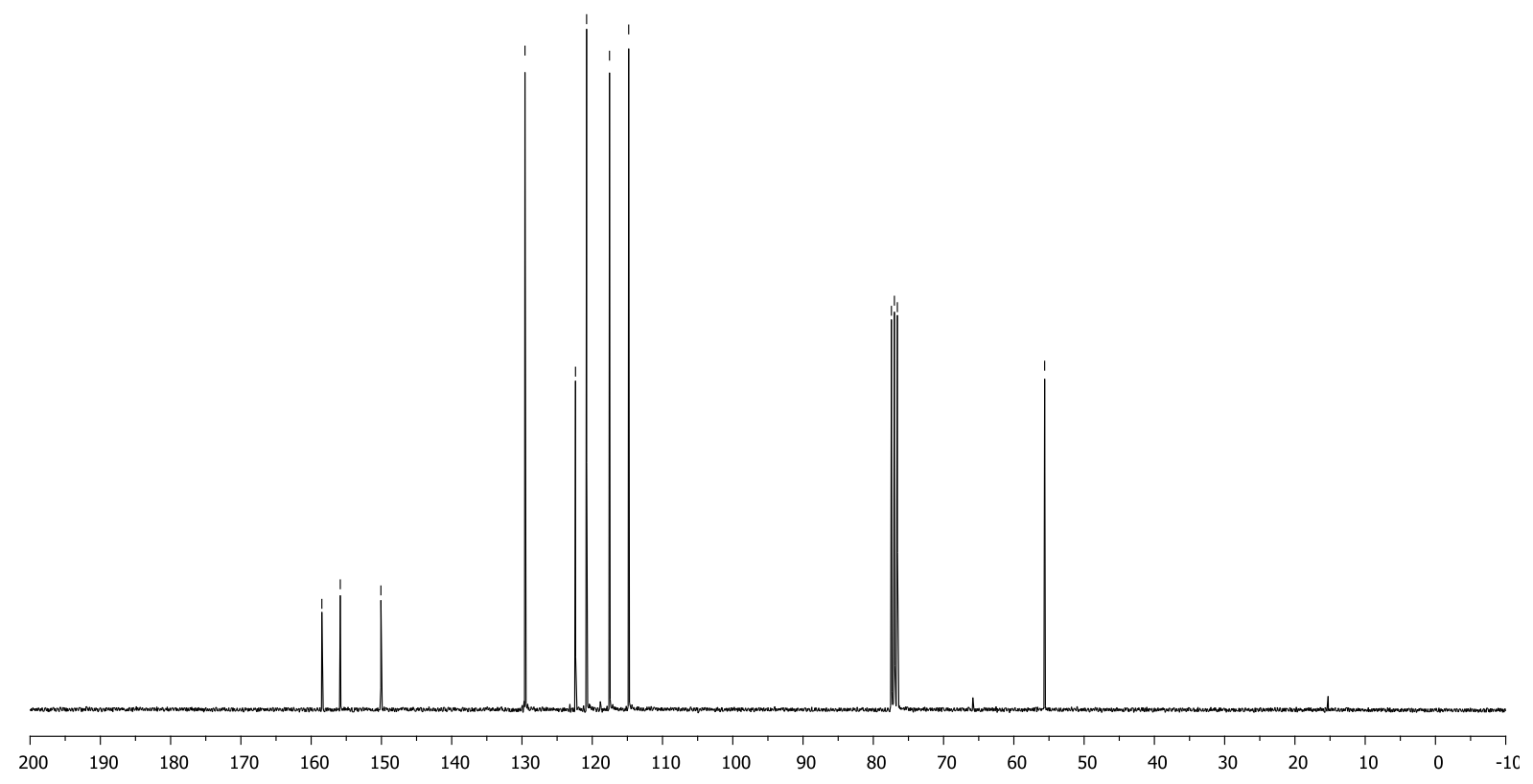


Supporting Information

SF
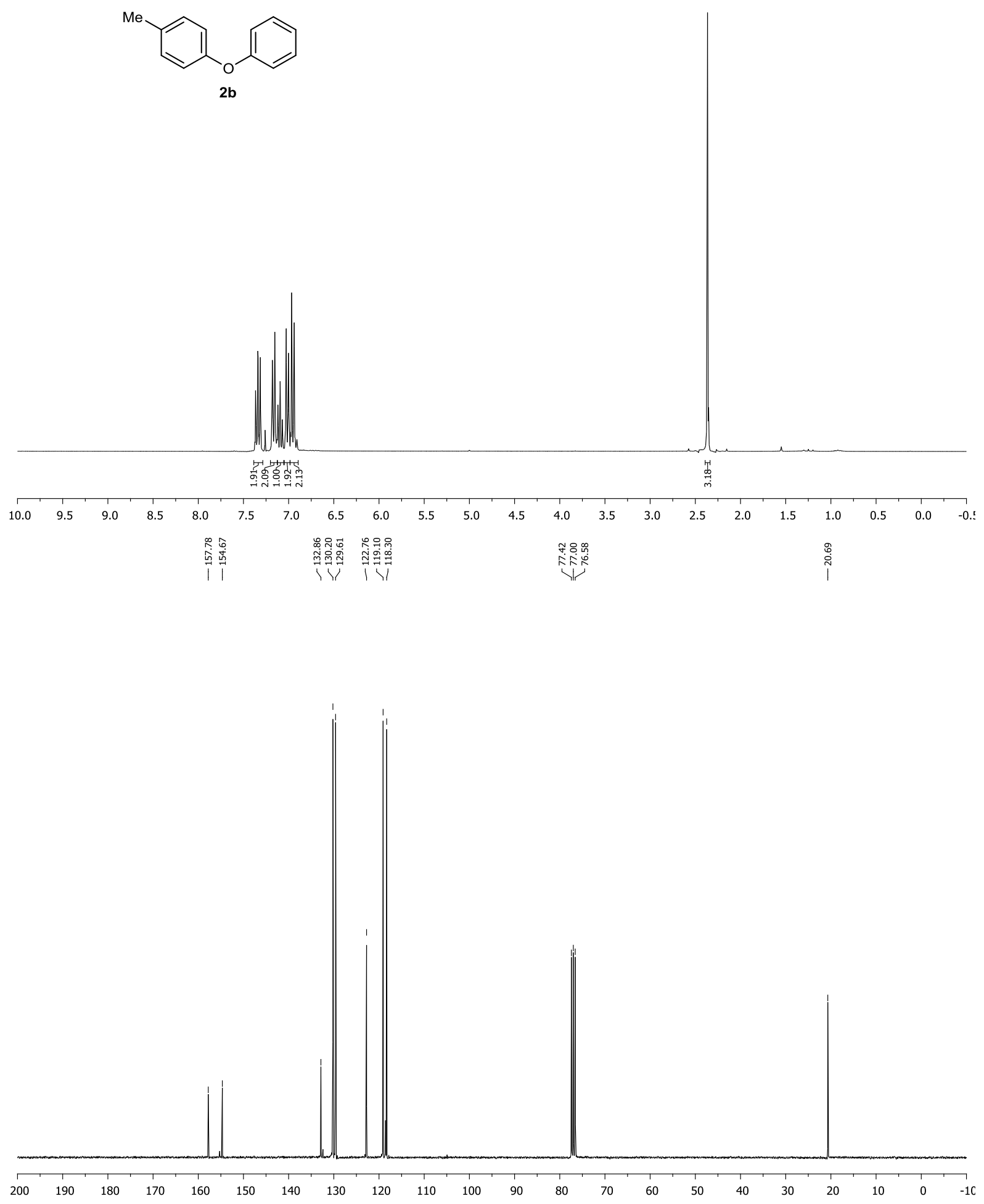
Supporting Information

Sb
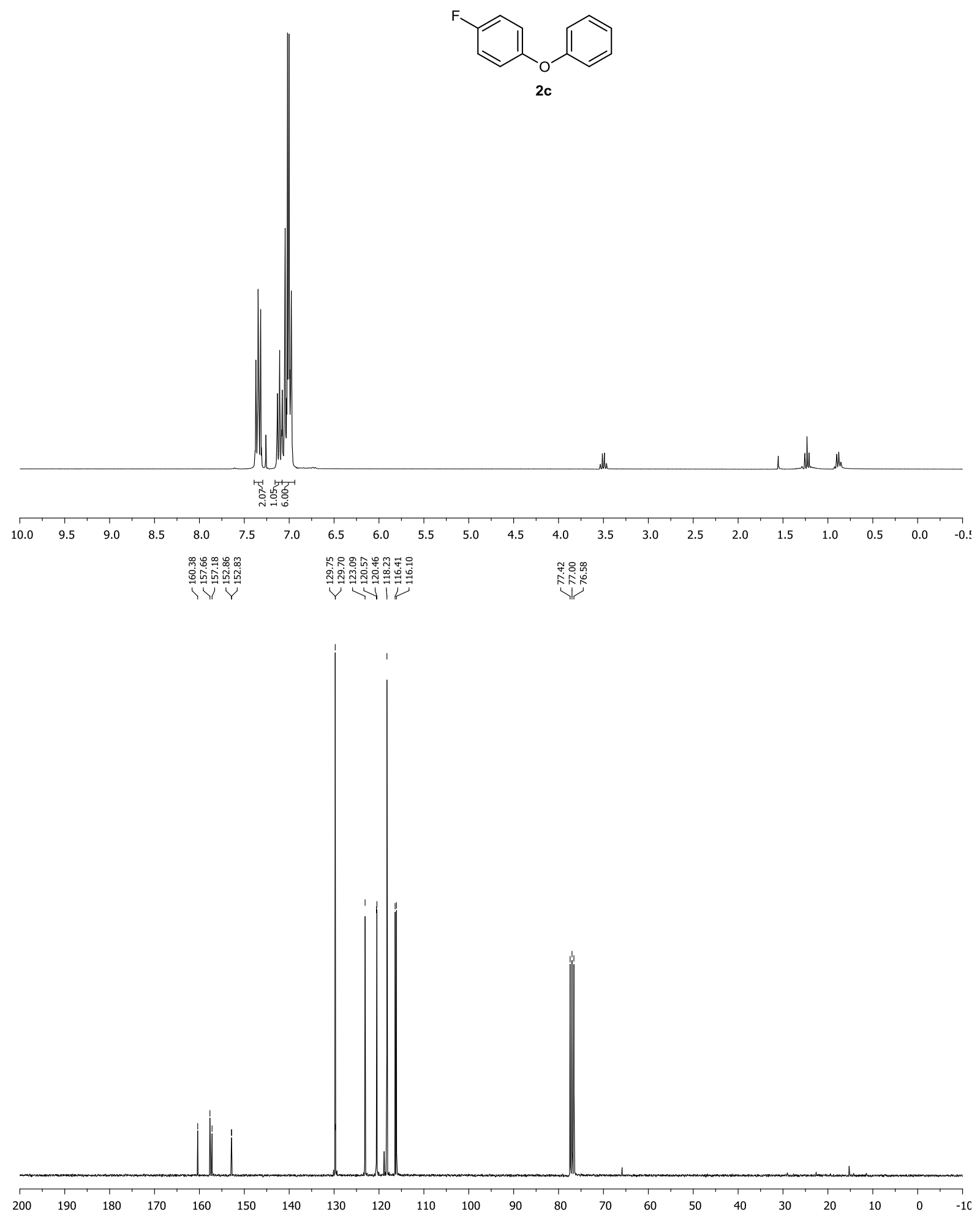
Supporting Information

ST
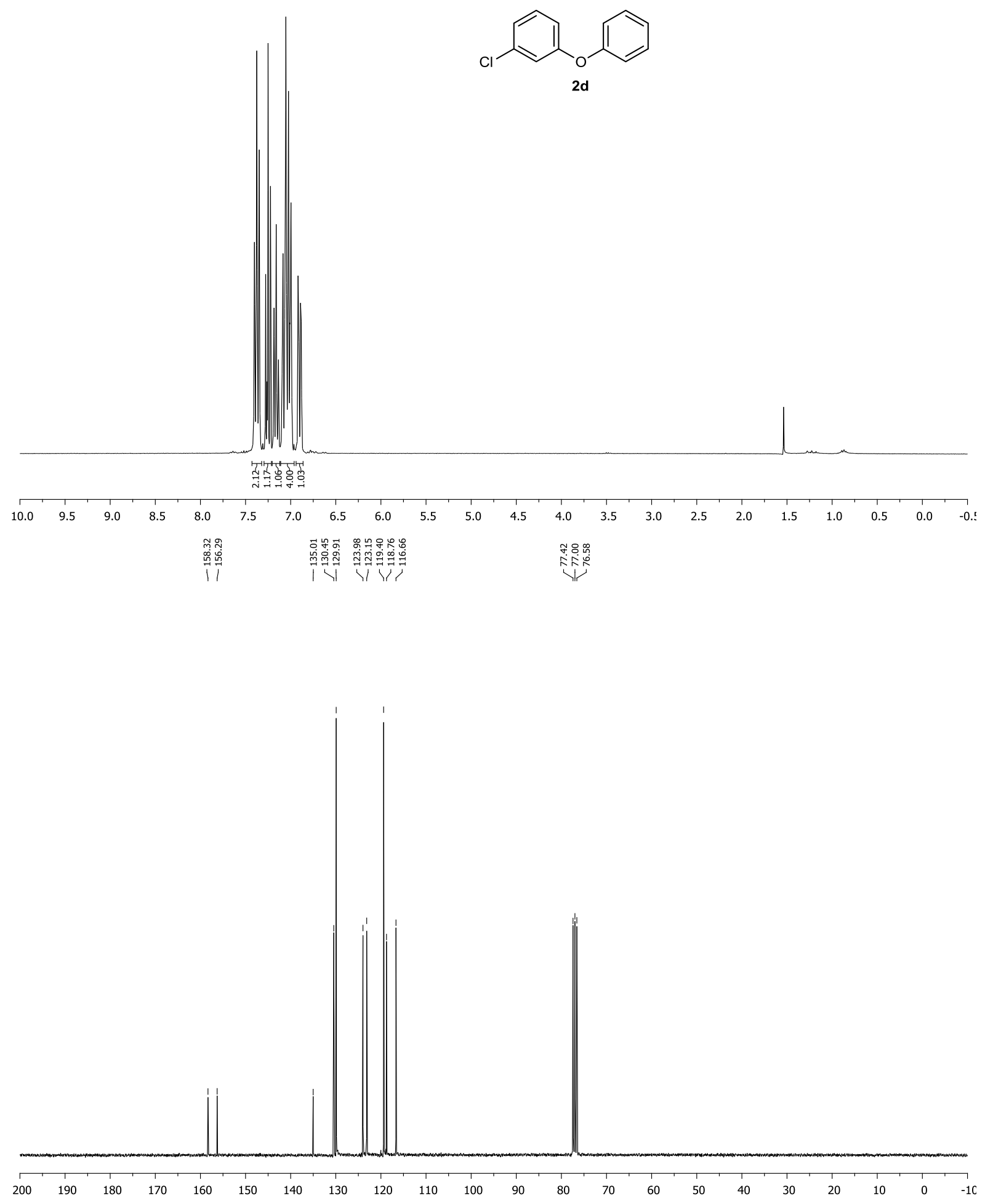
Supporting Information

58
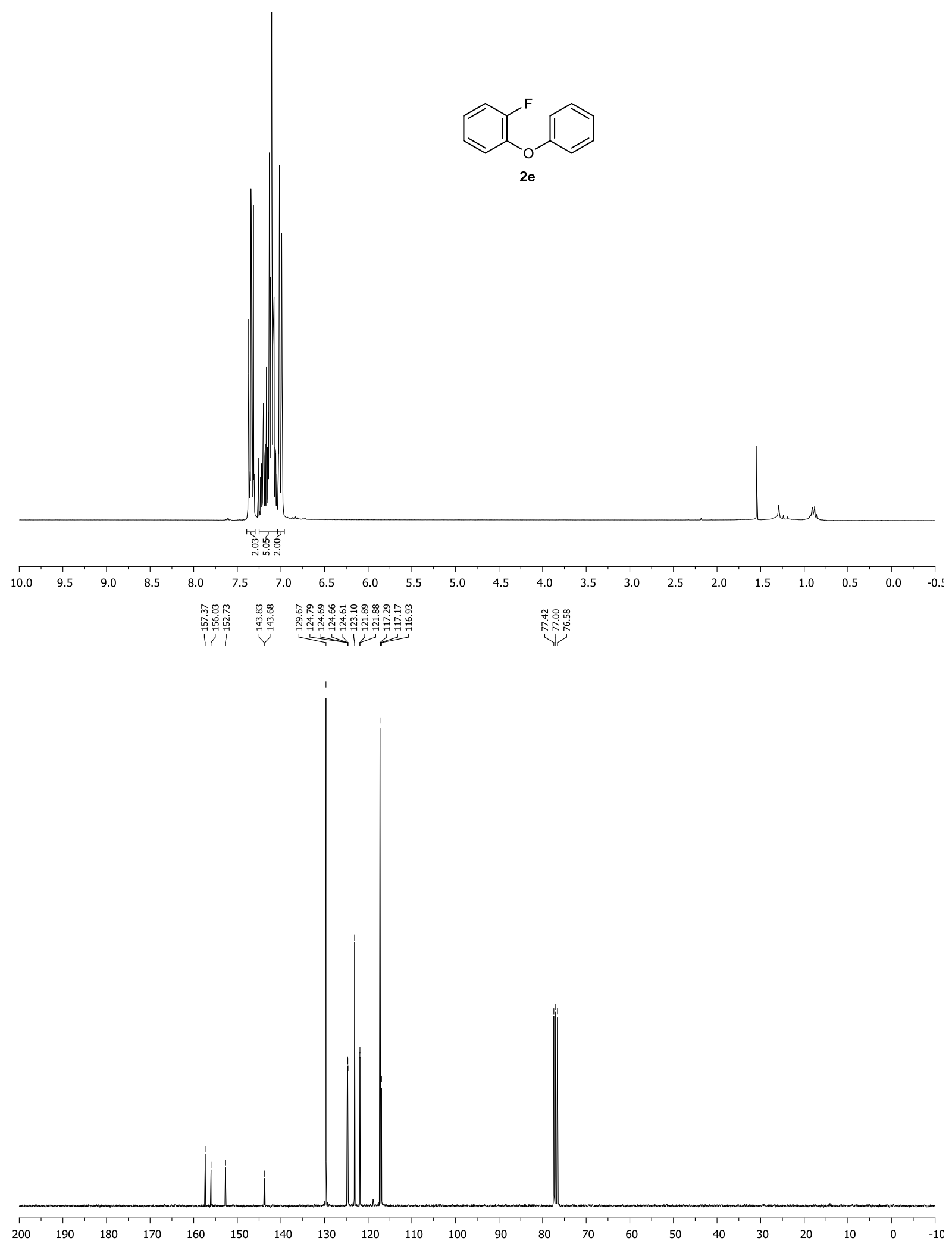
Supporting Information

Sq
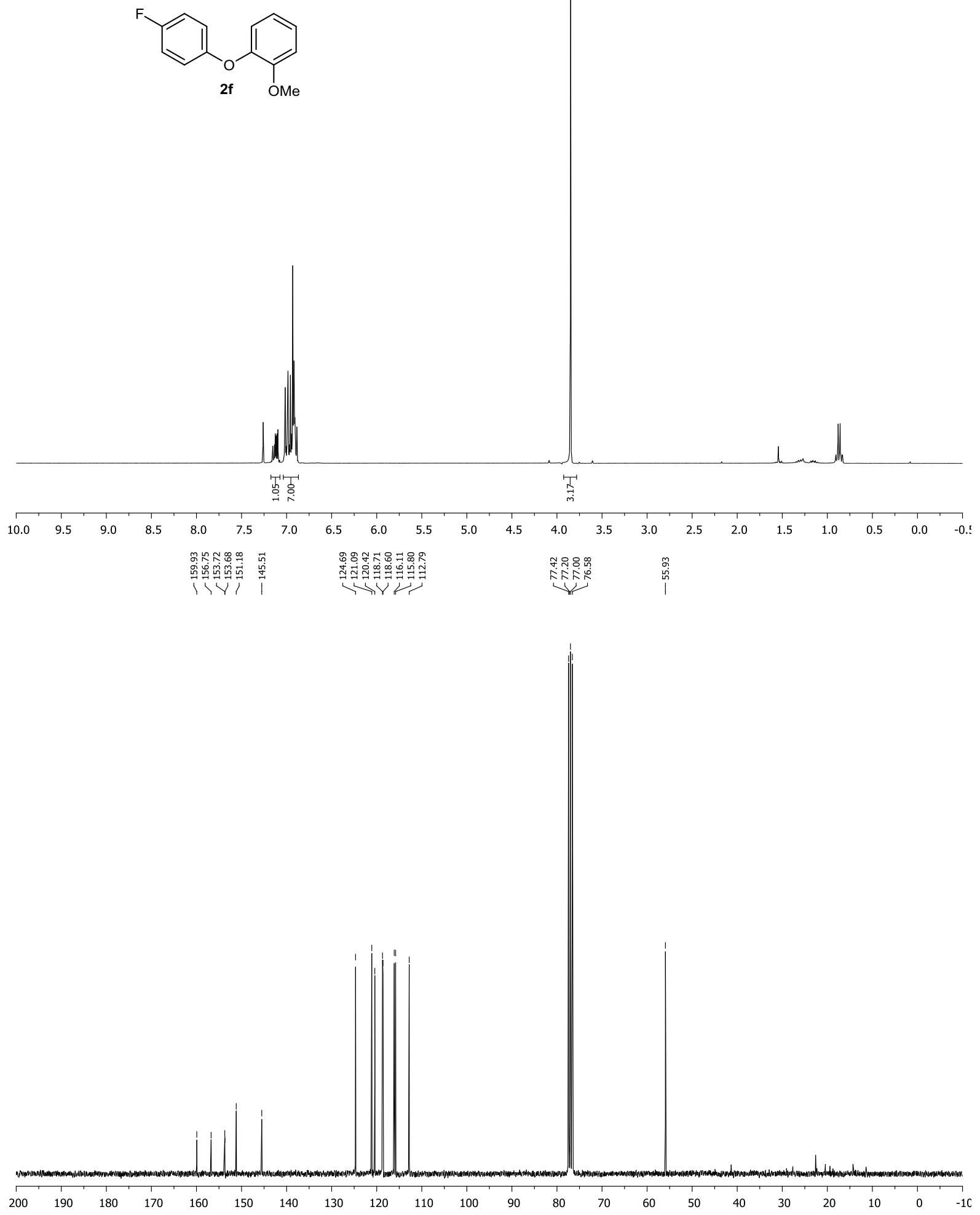
Supporting Information

S10
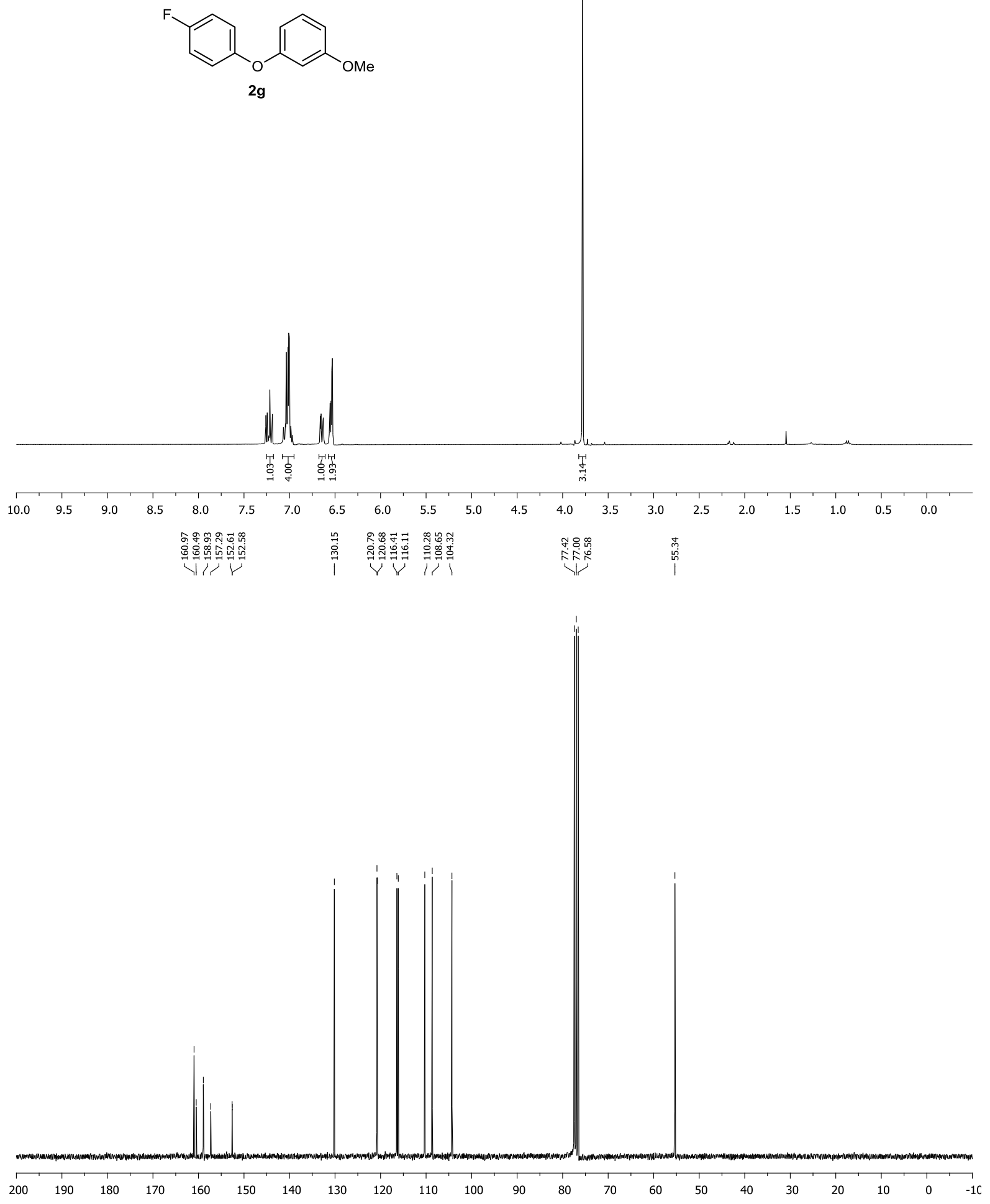

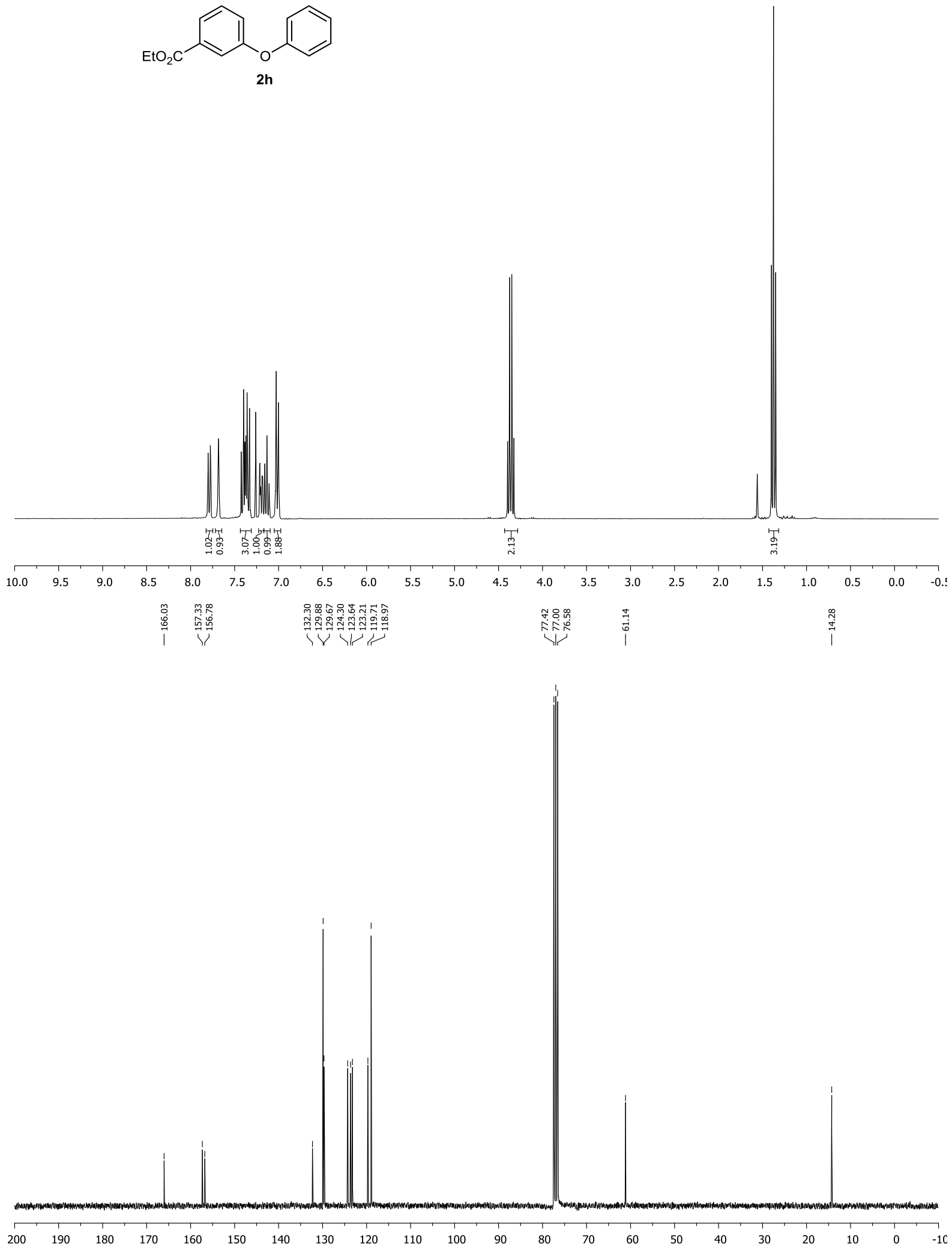

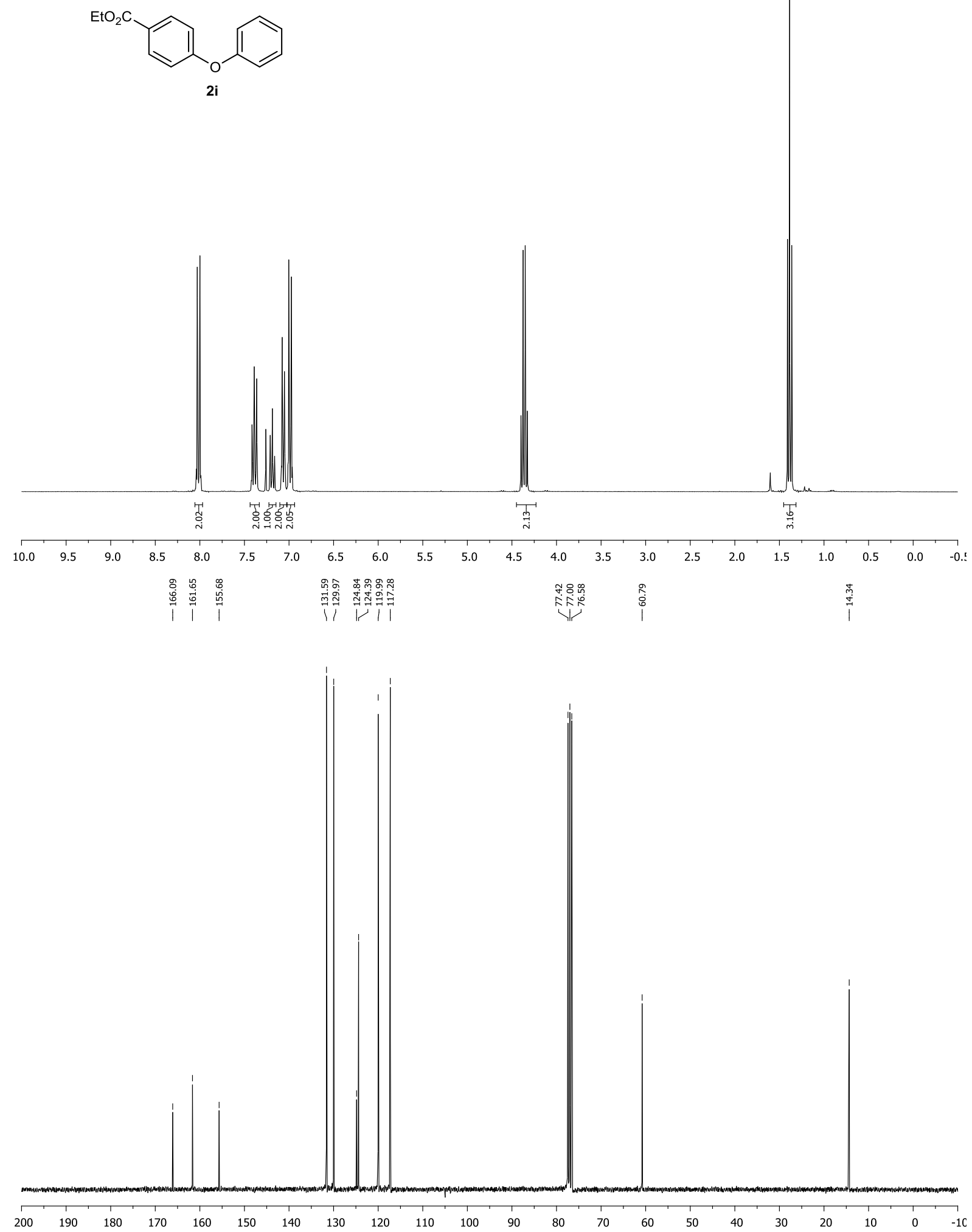
Supporting Information

S13

4. NMR spectra for compounds 7-13
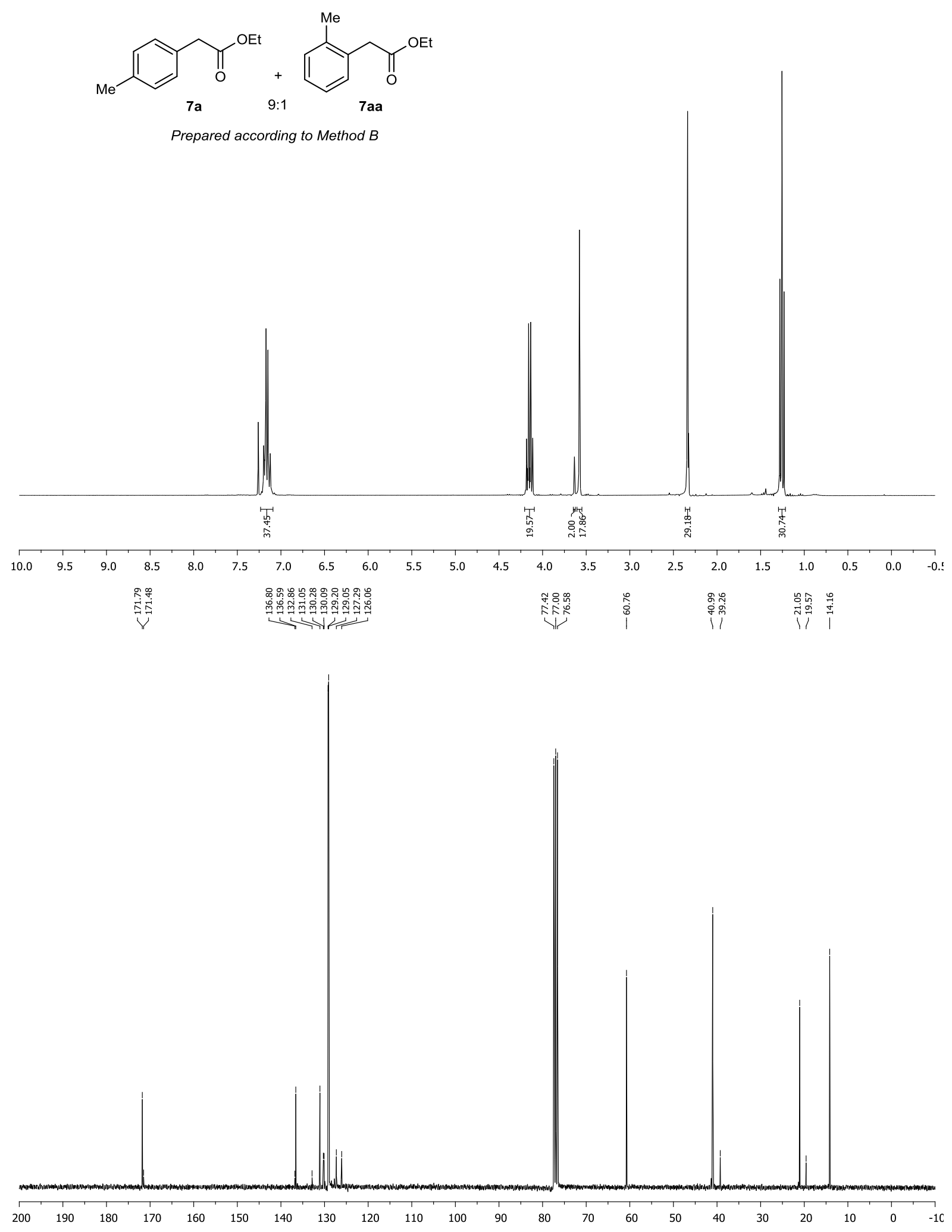
Supporting Information

S14
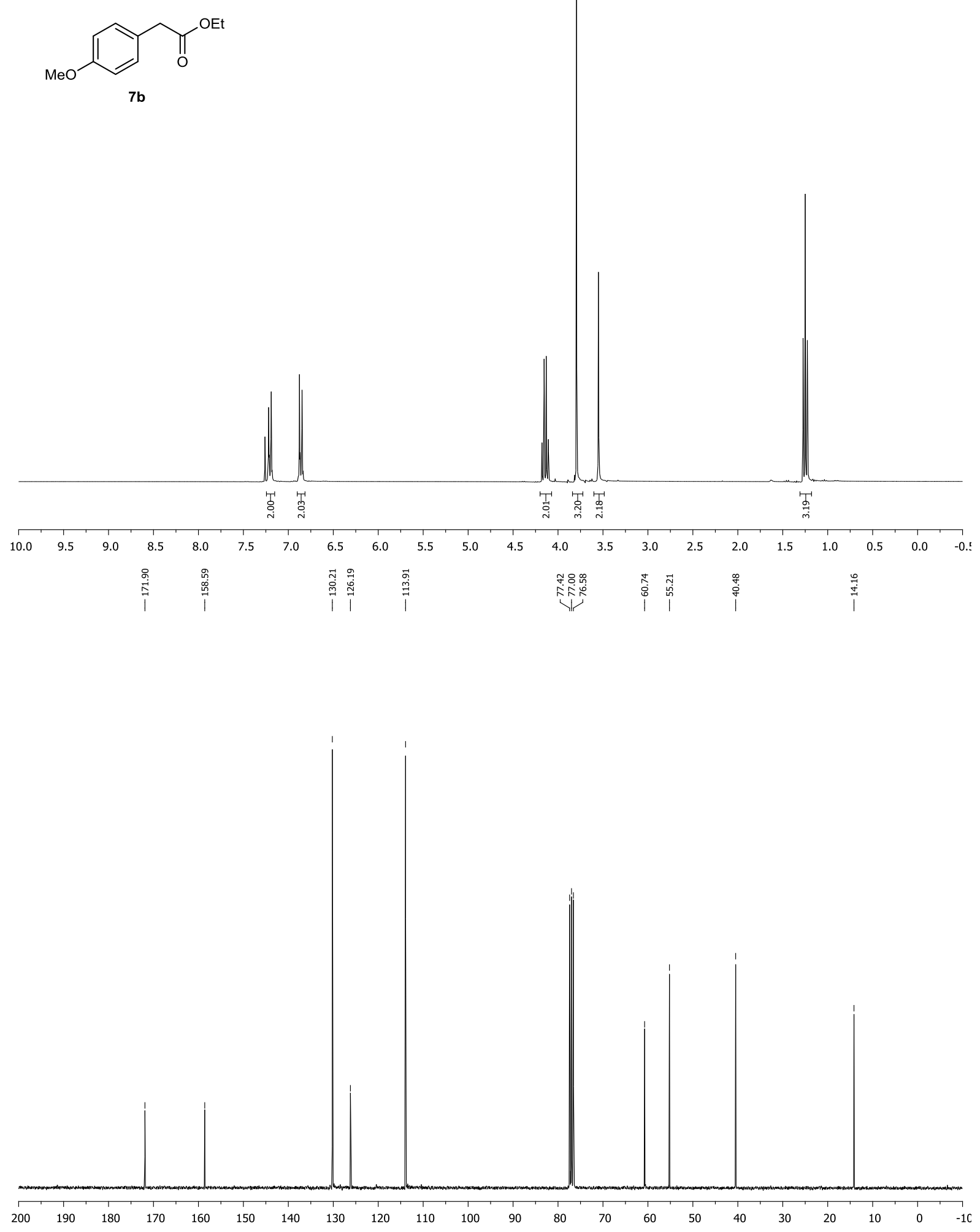
Supporting Information

S15

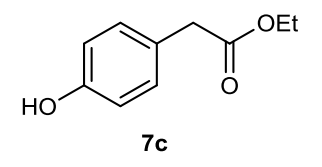

Prepared according to Method B
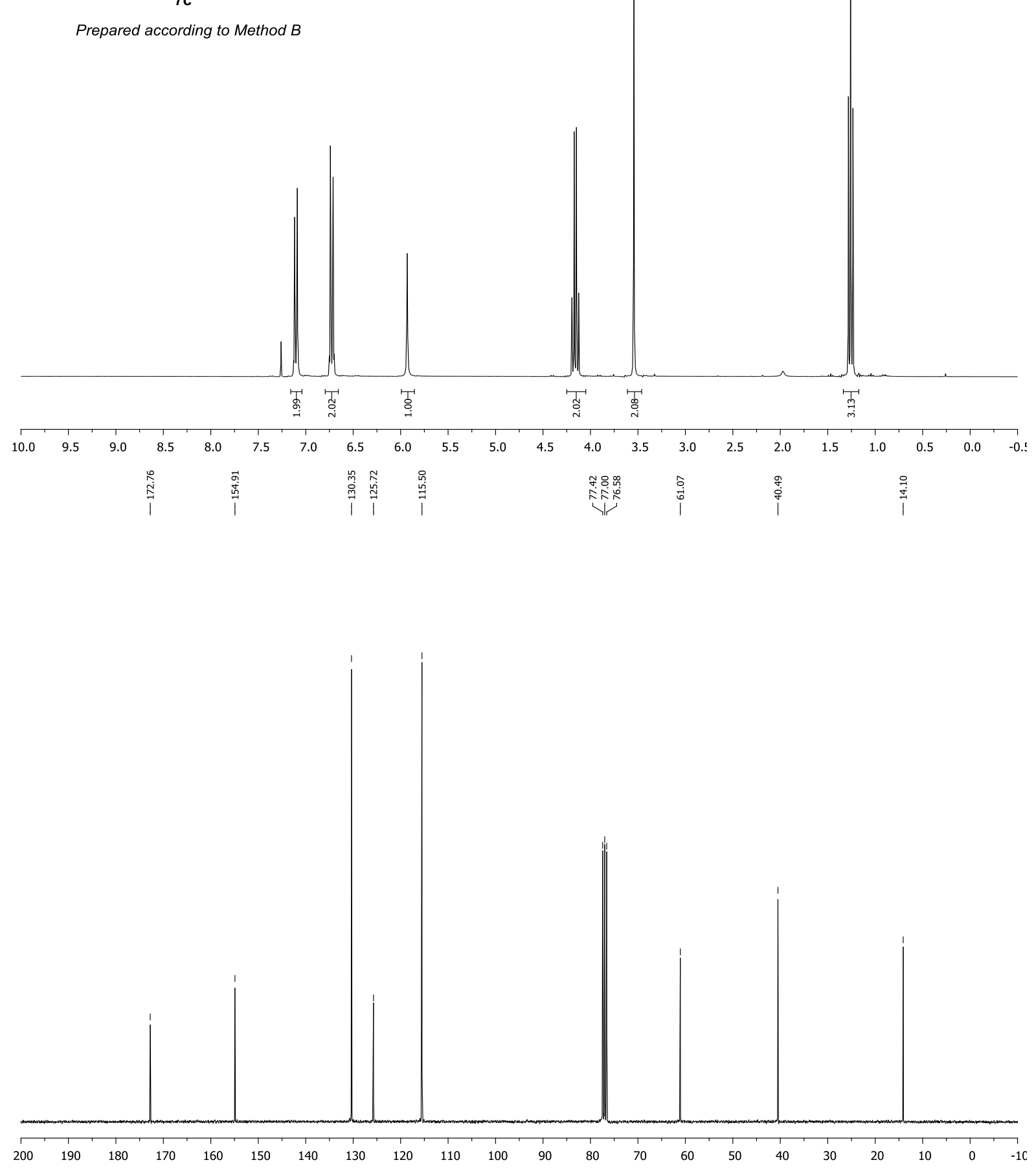
Supporting Information

S16
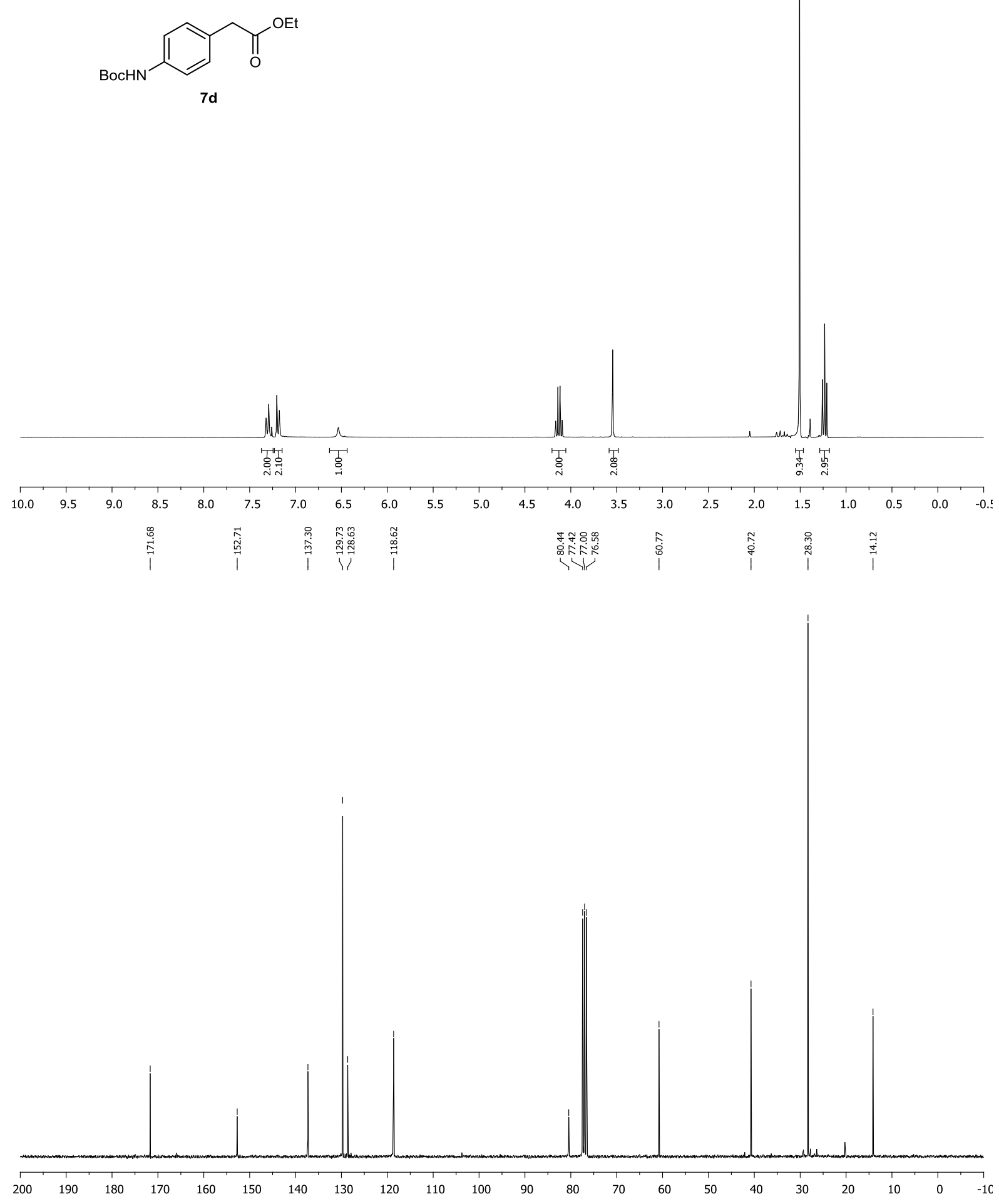
<smiles>CCOC(=O)Cc1ccc(Oc2ccc(OC)cc2)cc1</smiles>

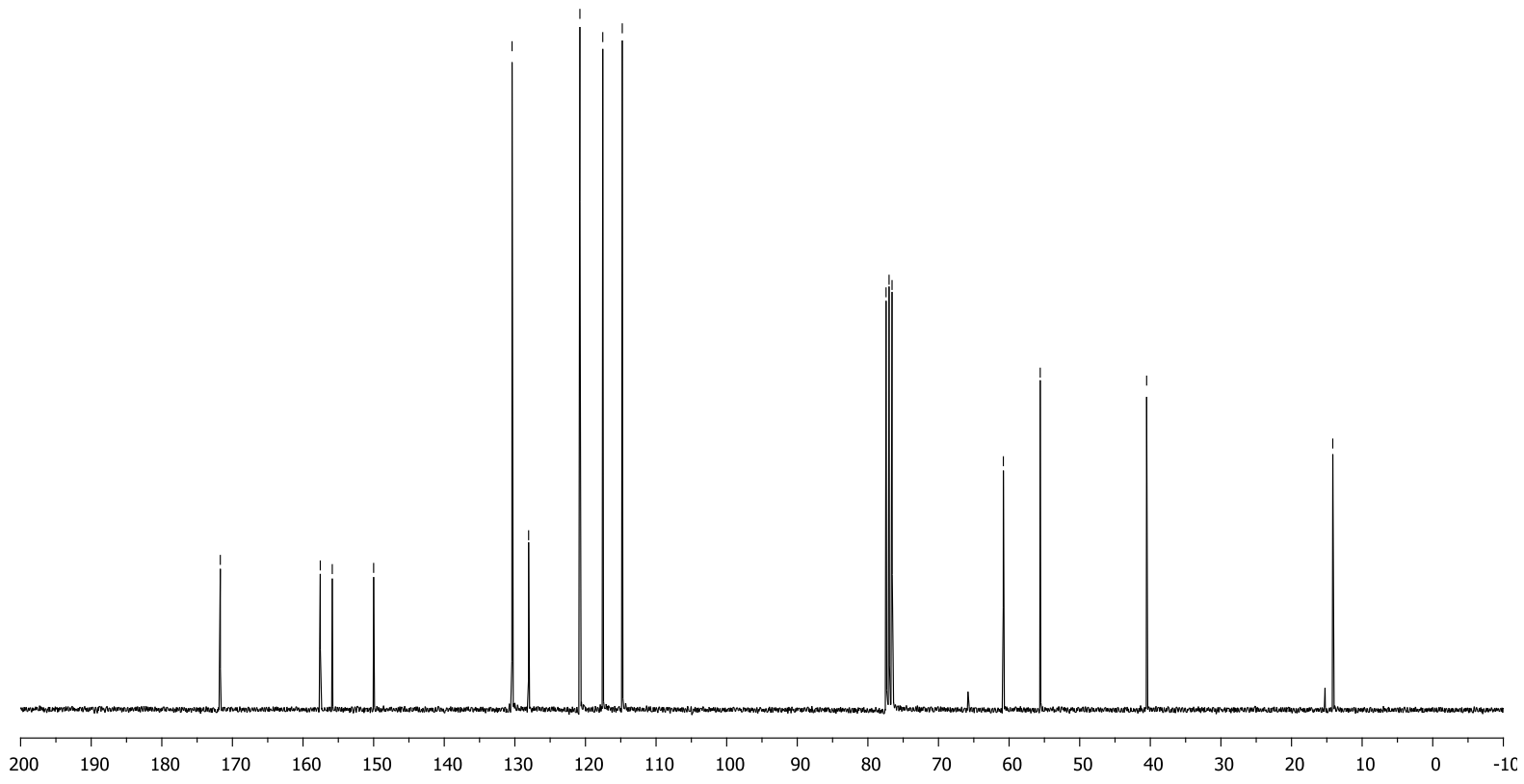


<smiles>CCOC(=O)Cc1ccc(Oc2ccccc2)cc1</smiles>
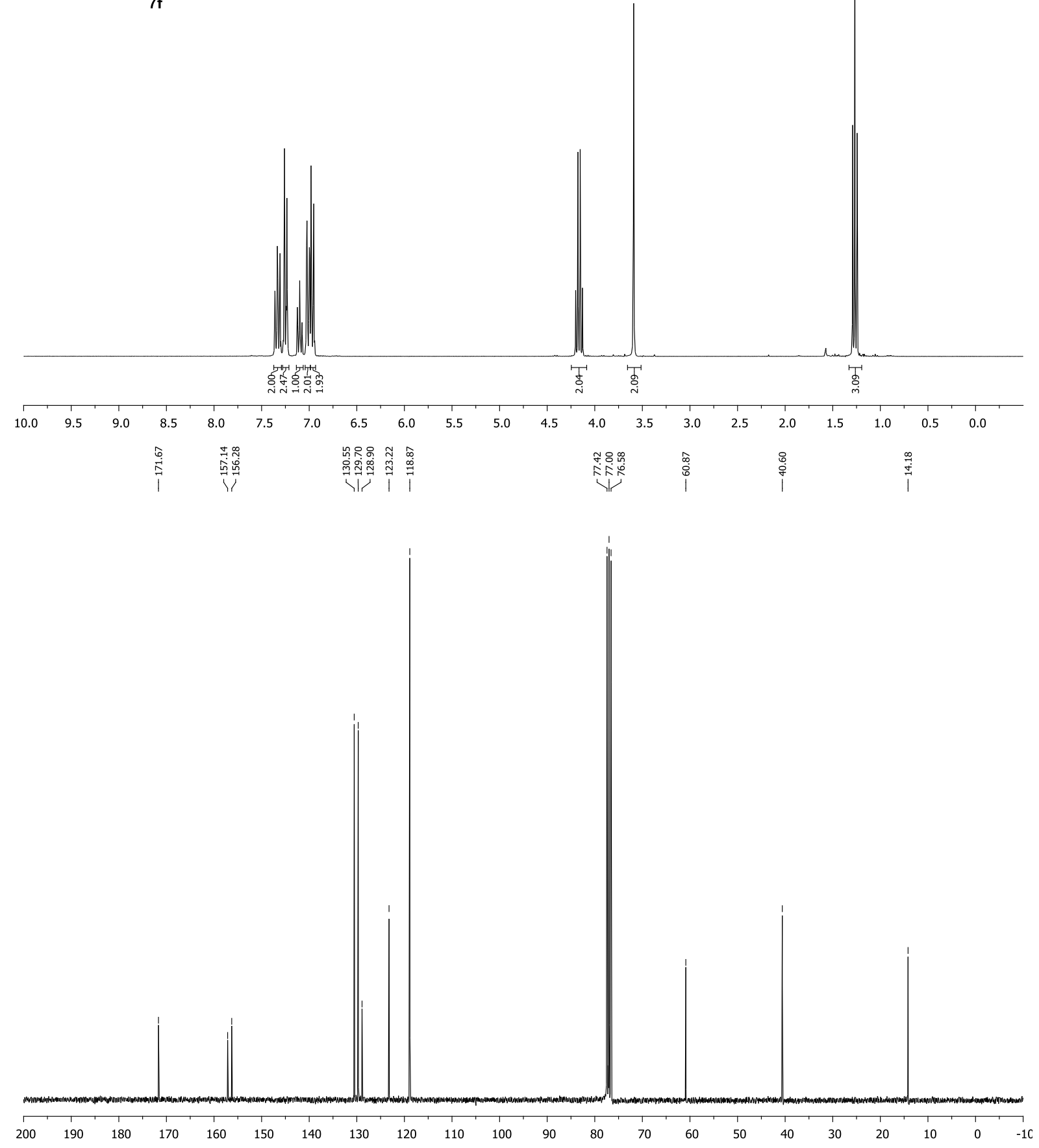

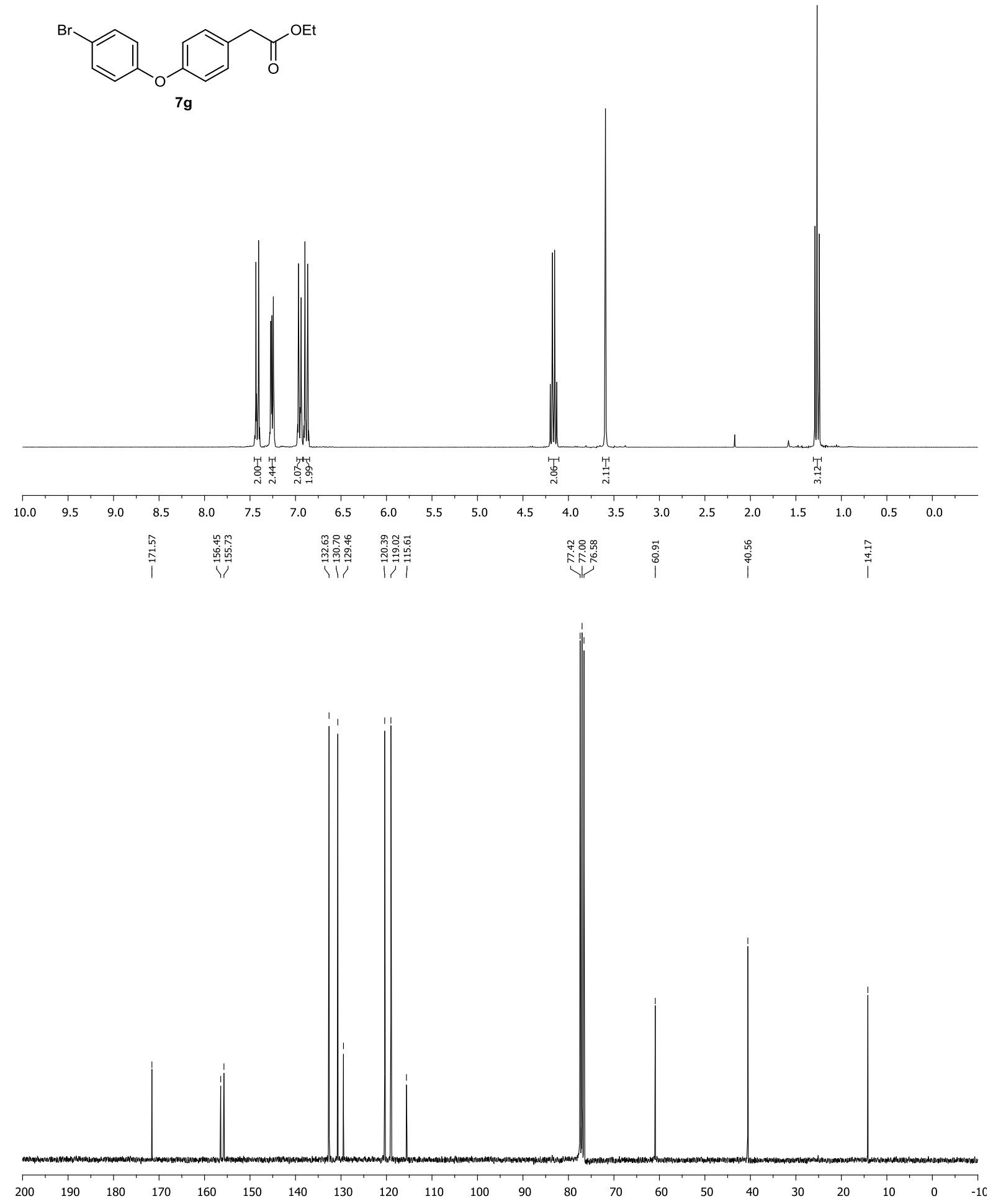
Supporting Information

S20
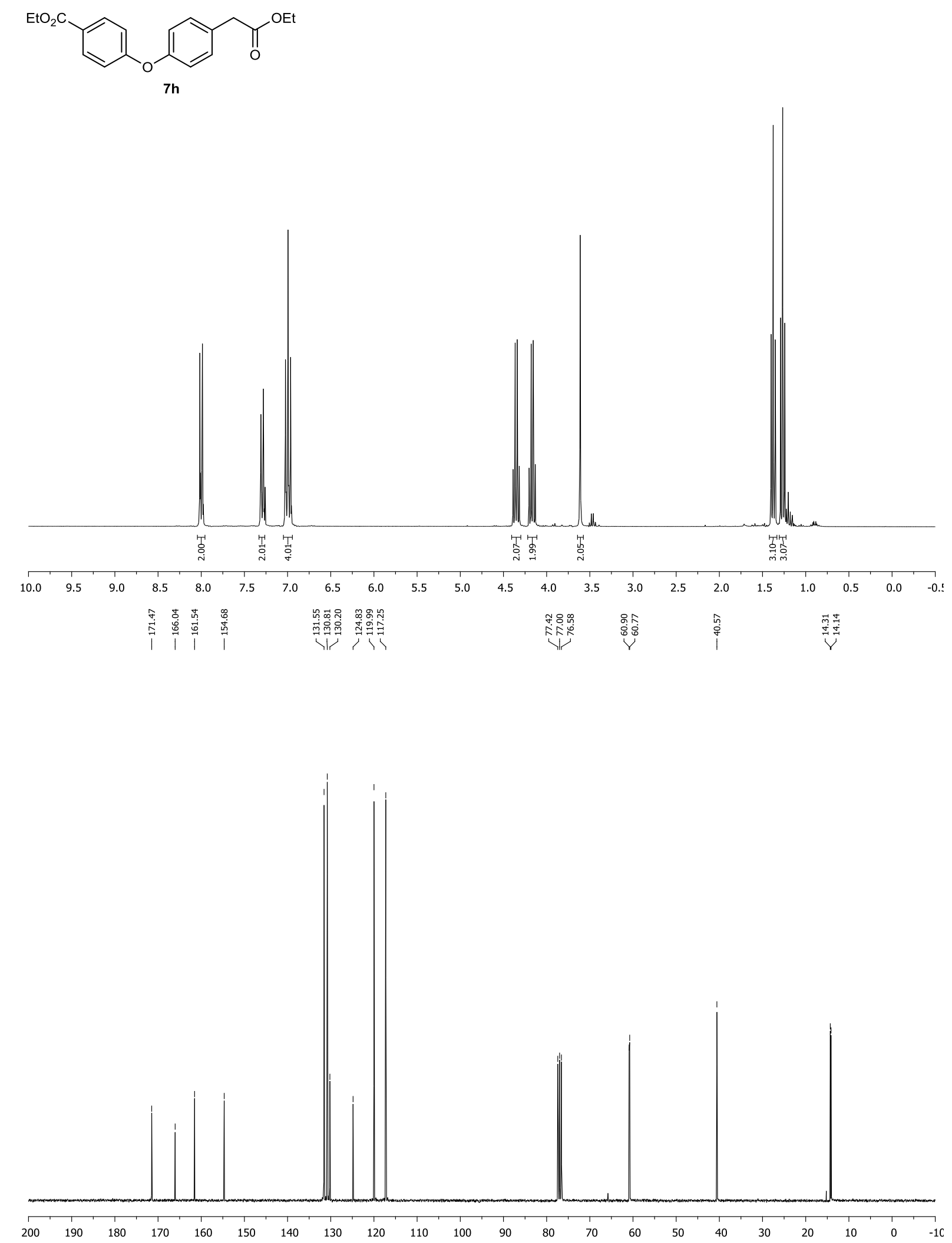
Supporting Information

S21
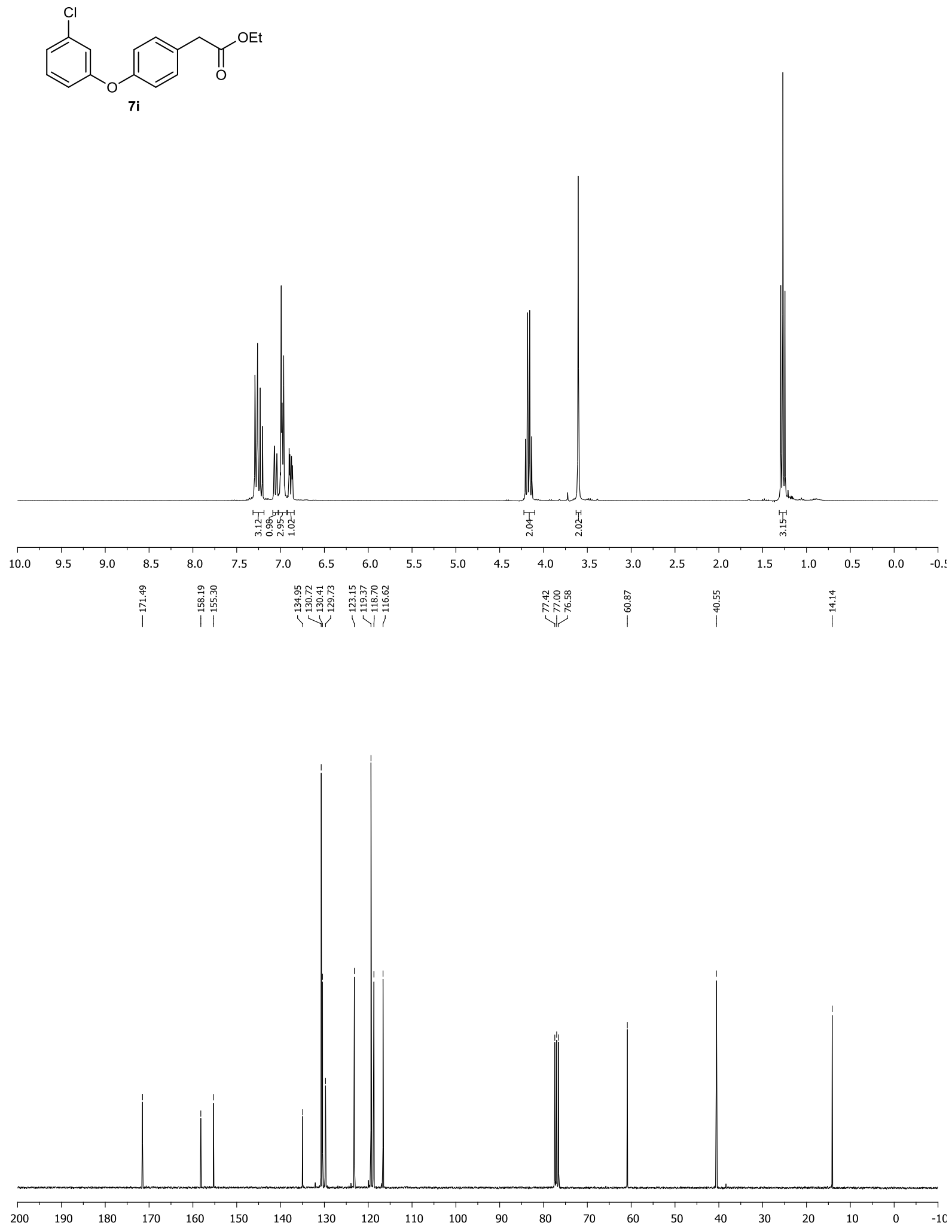
<smiles>CCOC(=O)Cc1ccc(Oc2cccc(C(=O)OCC)c2)cc1</smiles>
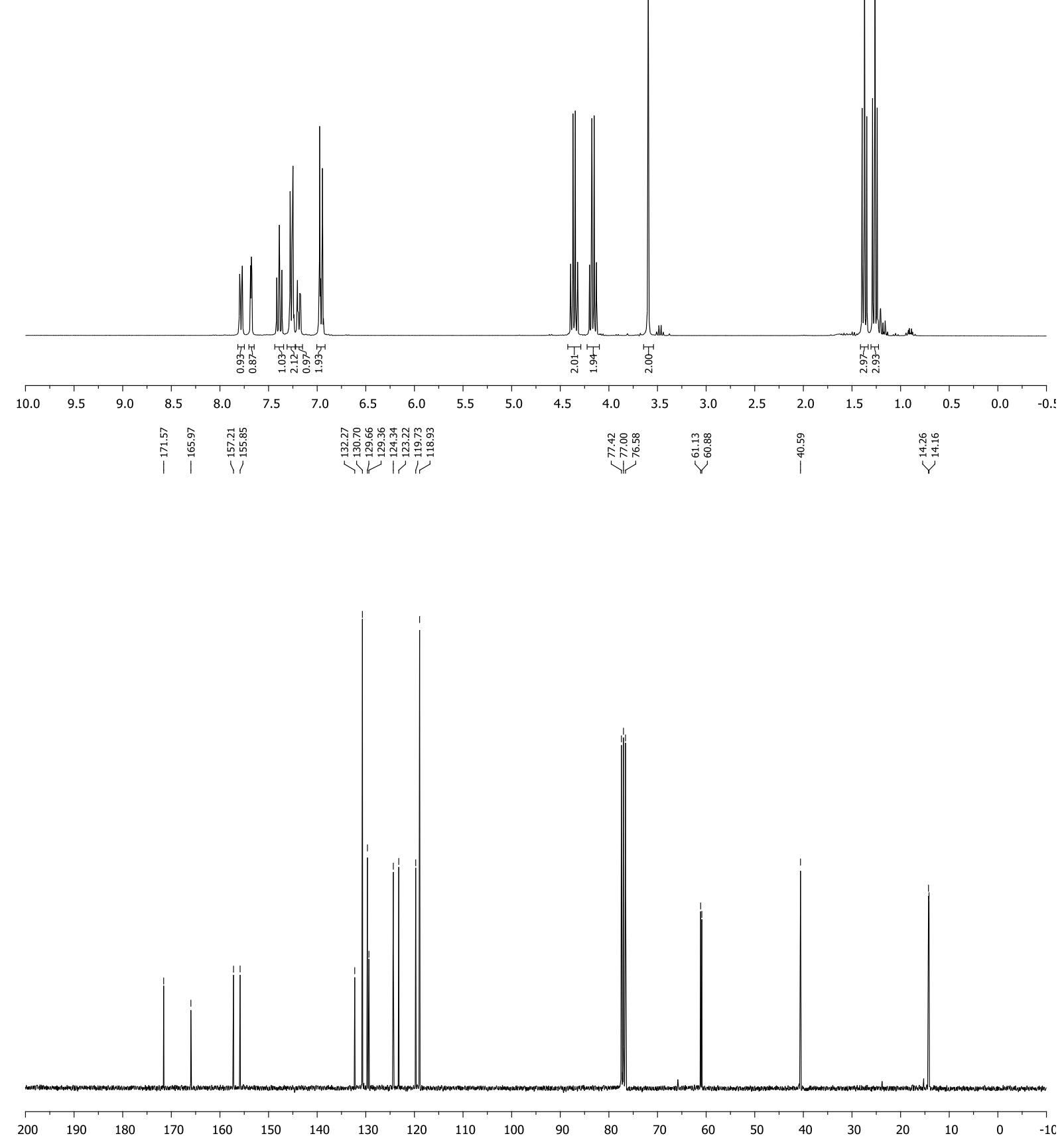
Supporting Information

S23
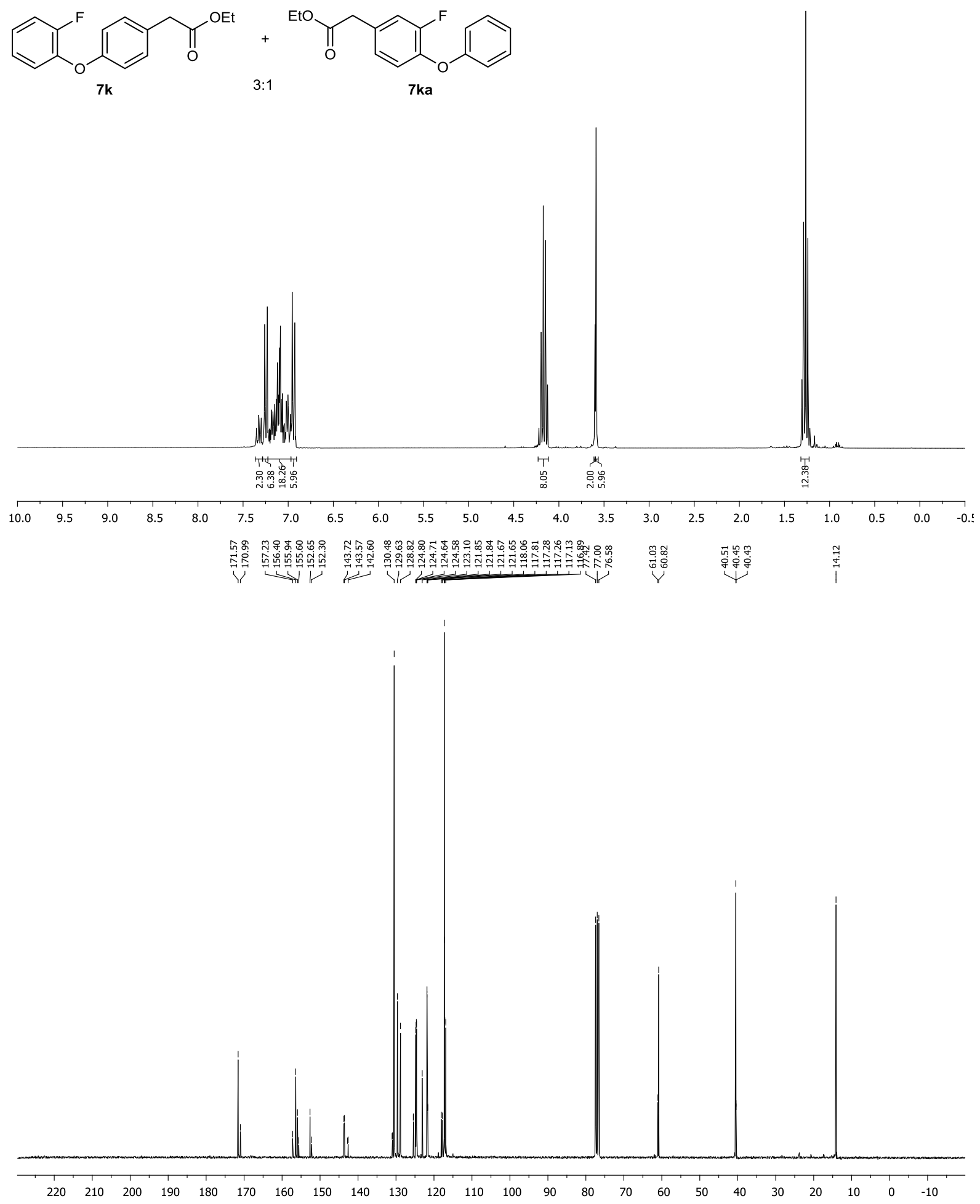
Supporting Information

S24
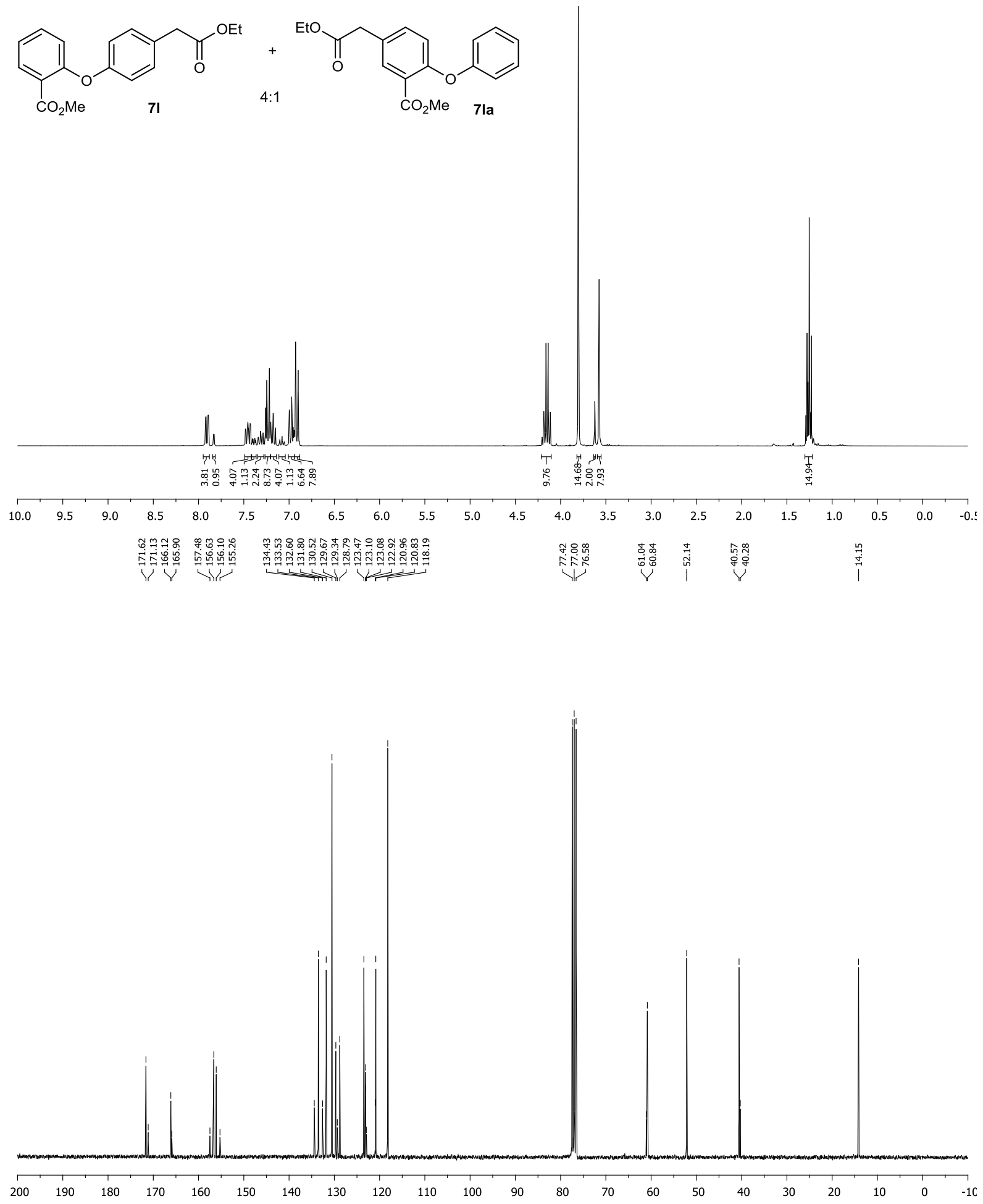
Supporting Information

S25

$C_{6} D_{6}$ spectrum
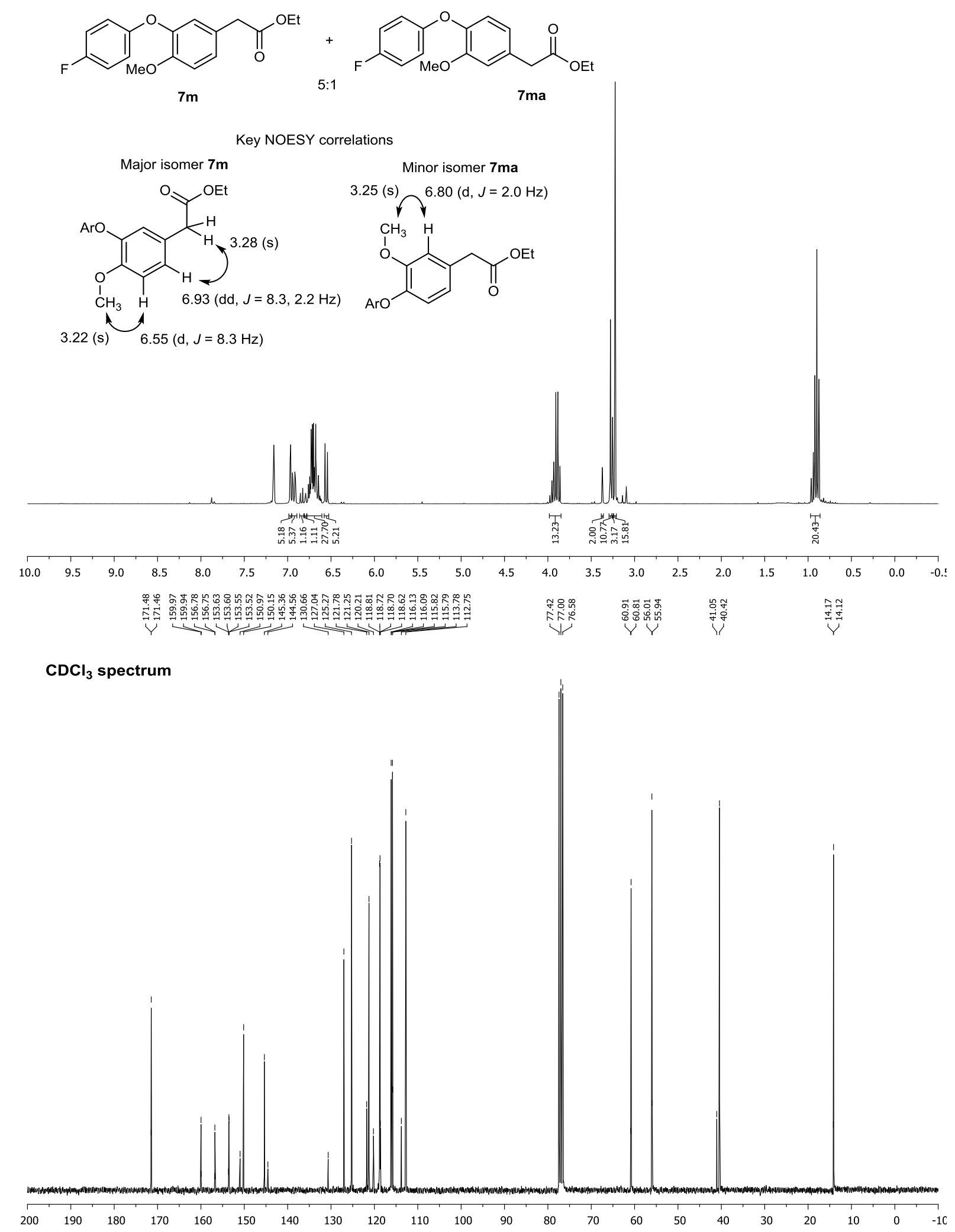
Supporting Information

S26
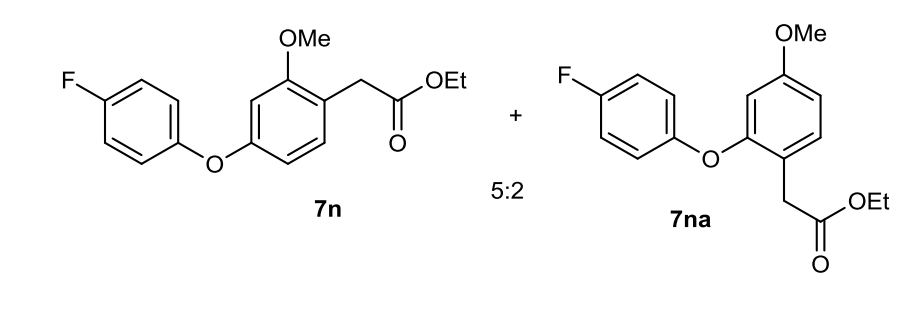

Minor isomer 7 na key NOESY correlation
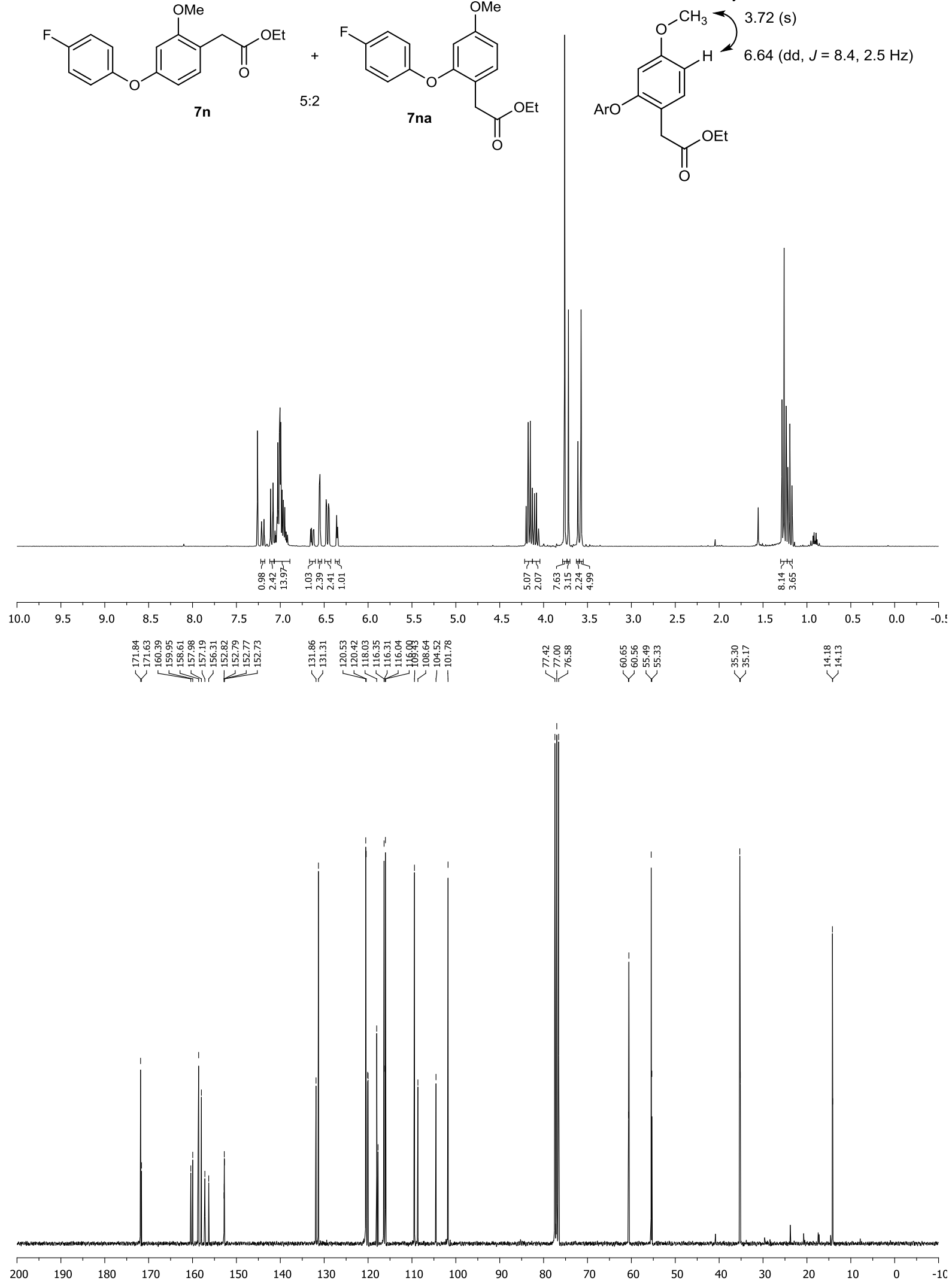
Supporting Information

S27
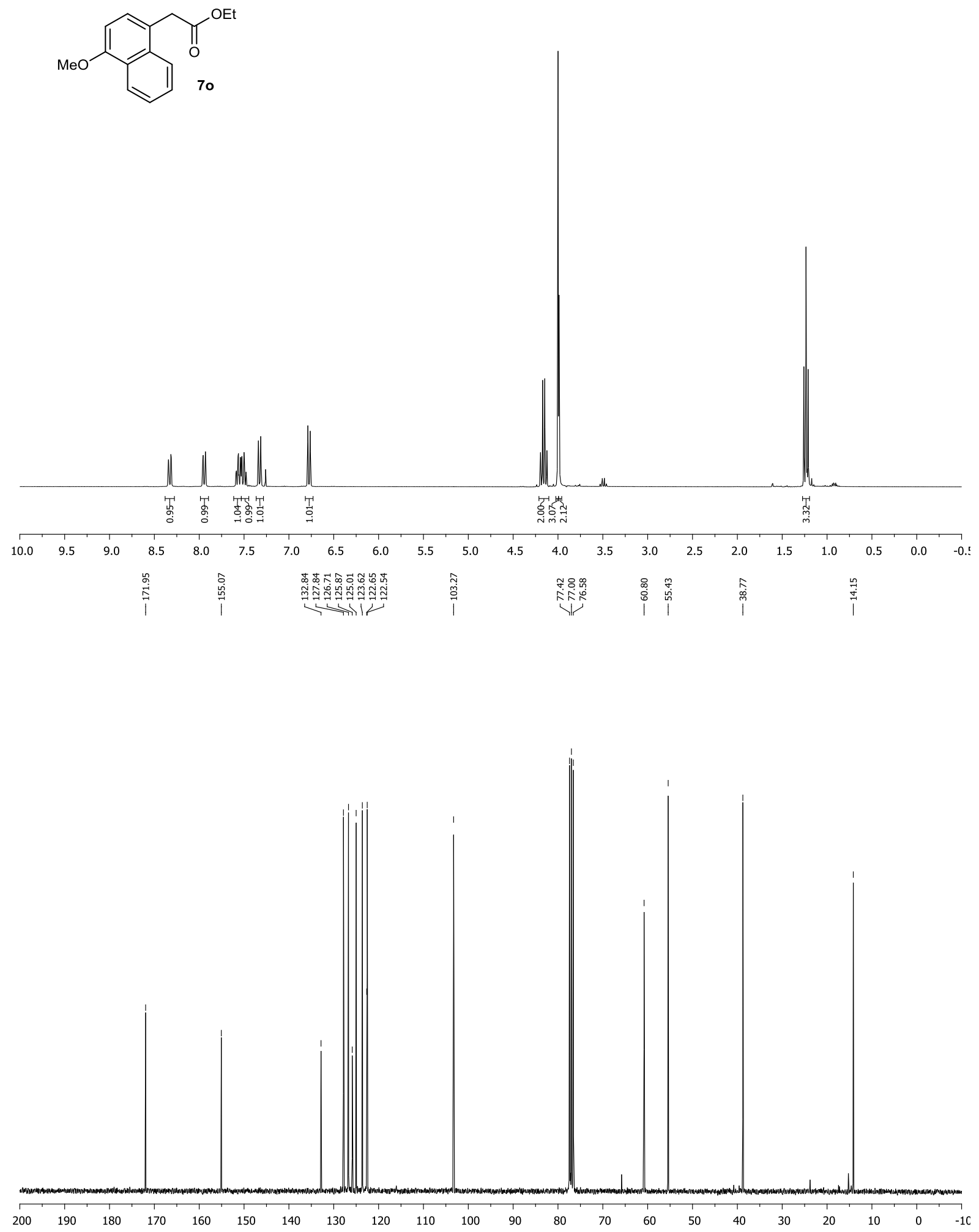
Supporting Information

S28
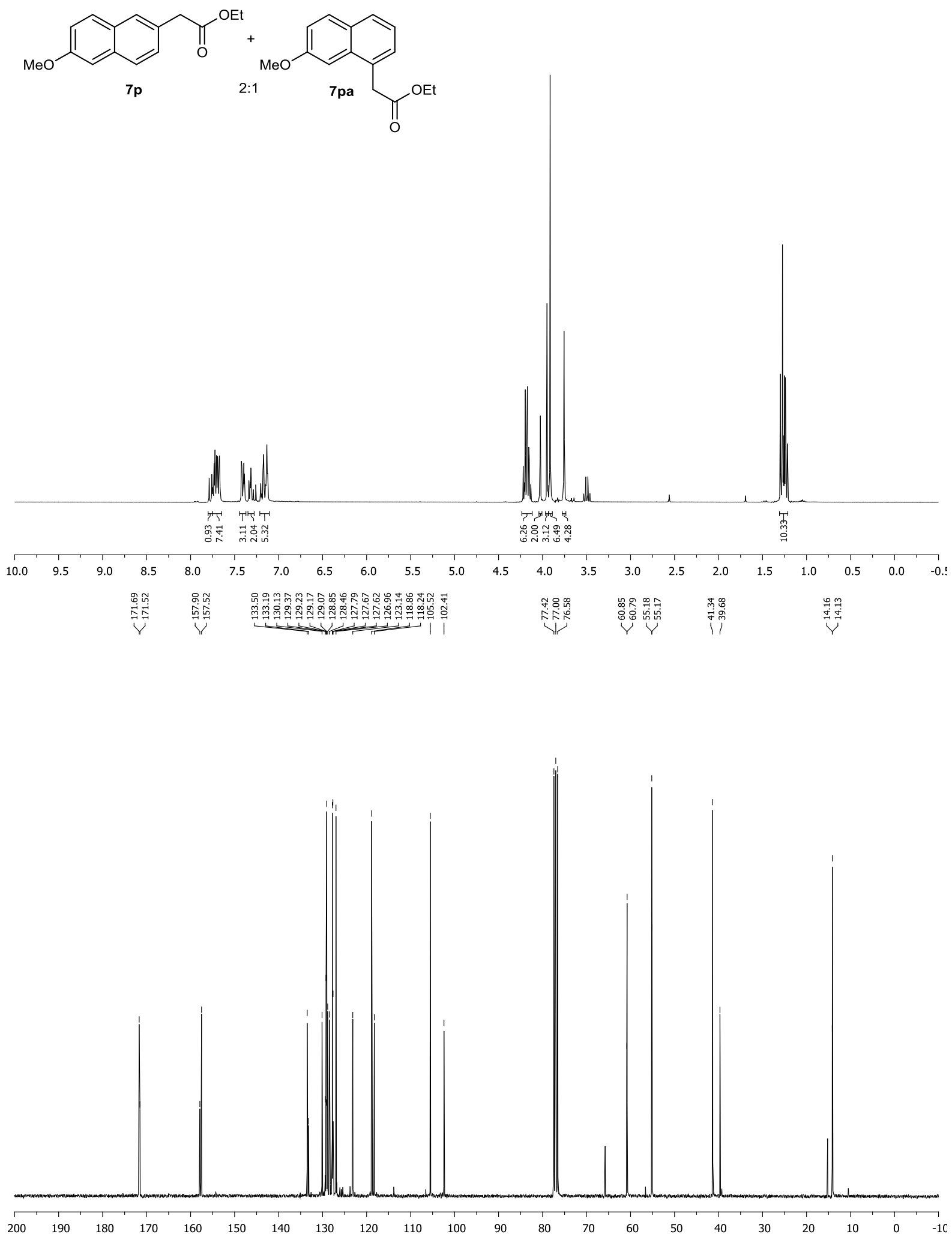
$\mathrm{CtO}_{\mathbf{8}} \mathrm{C}$
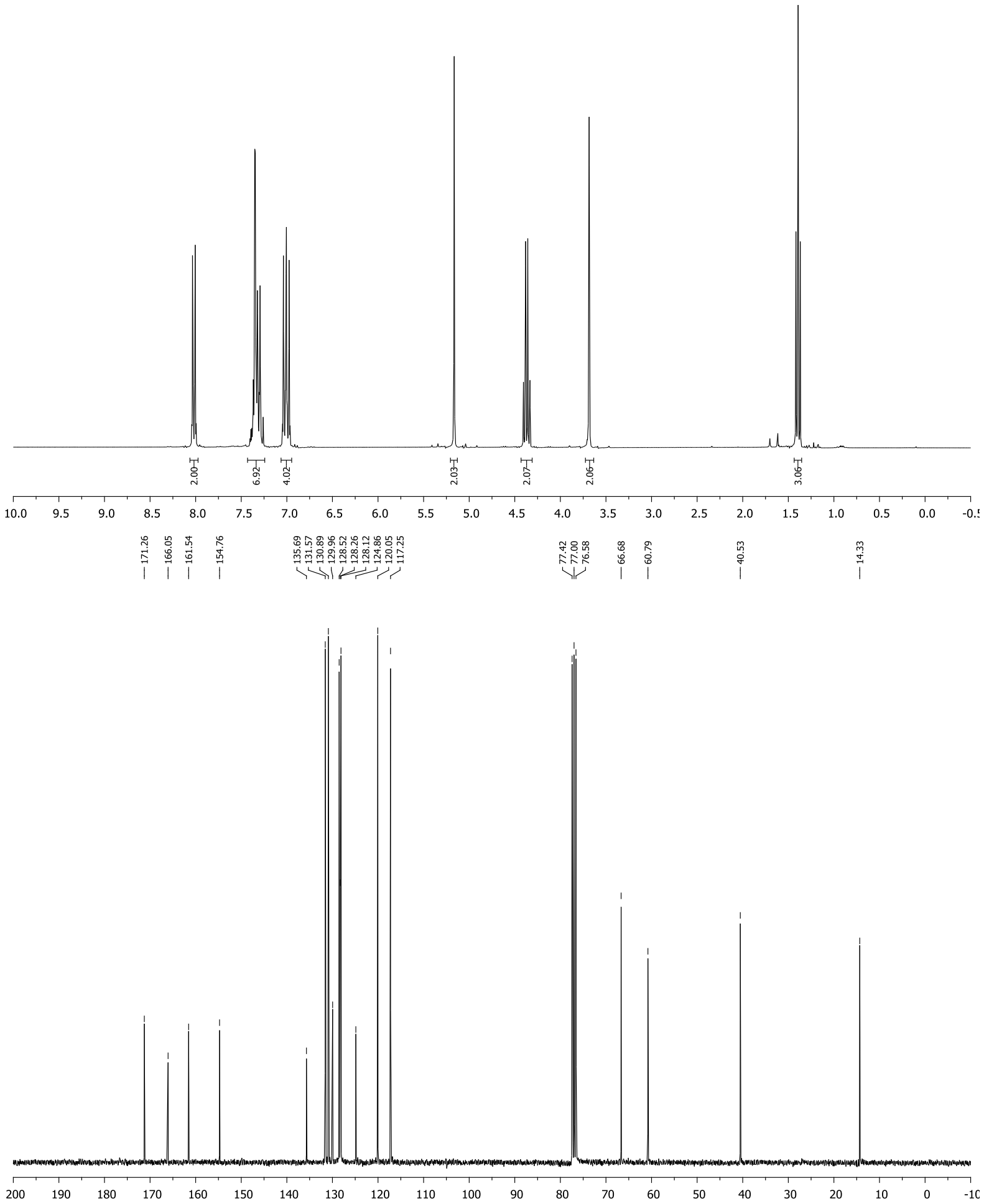
Supporting Information

S30
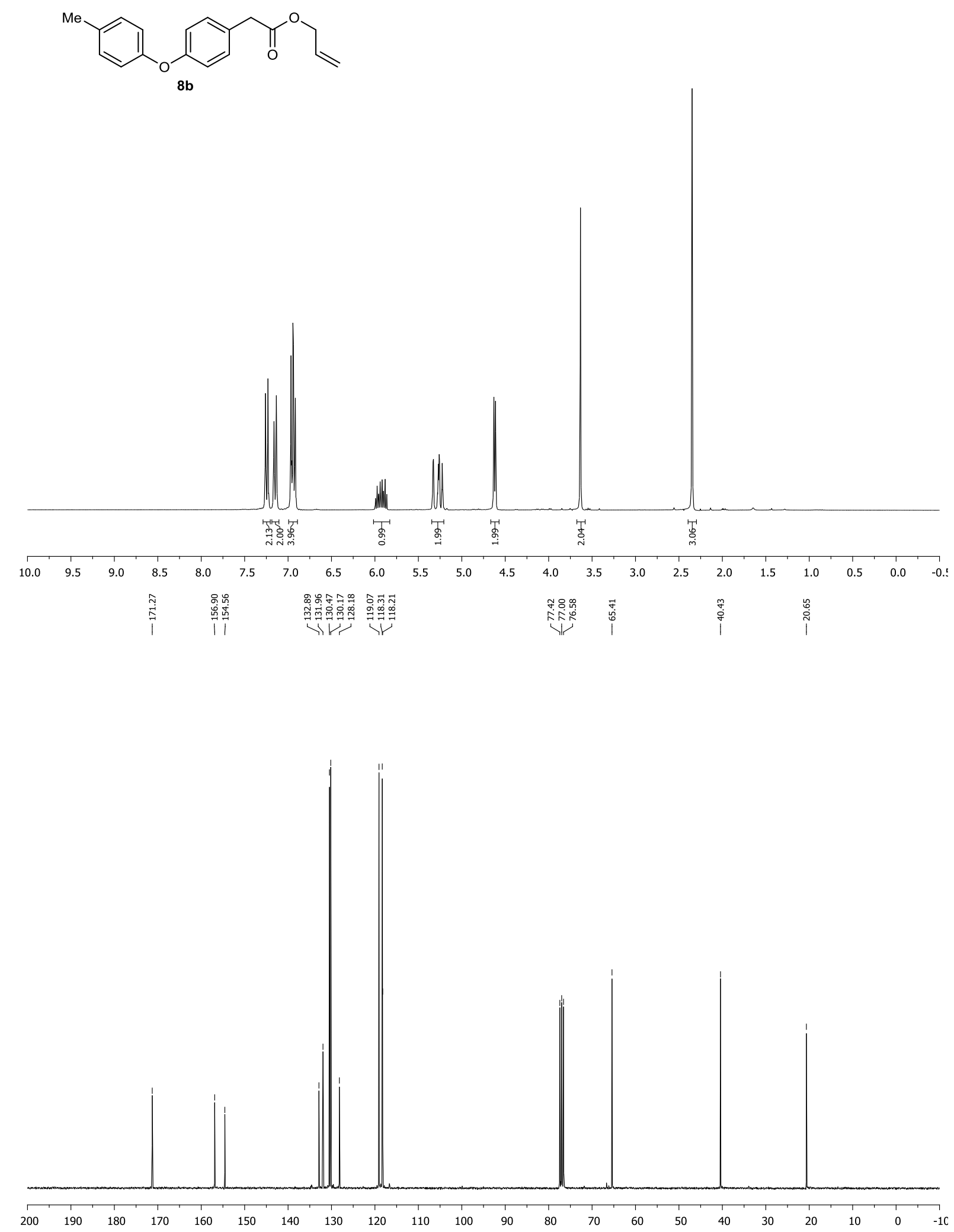
Supporting Information

S31
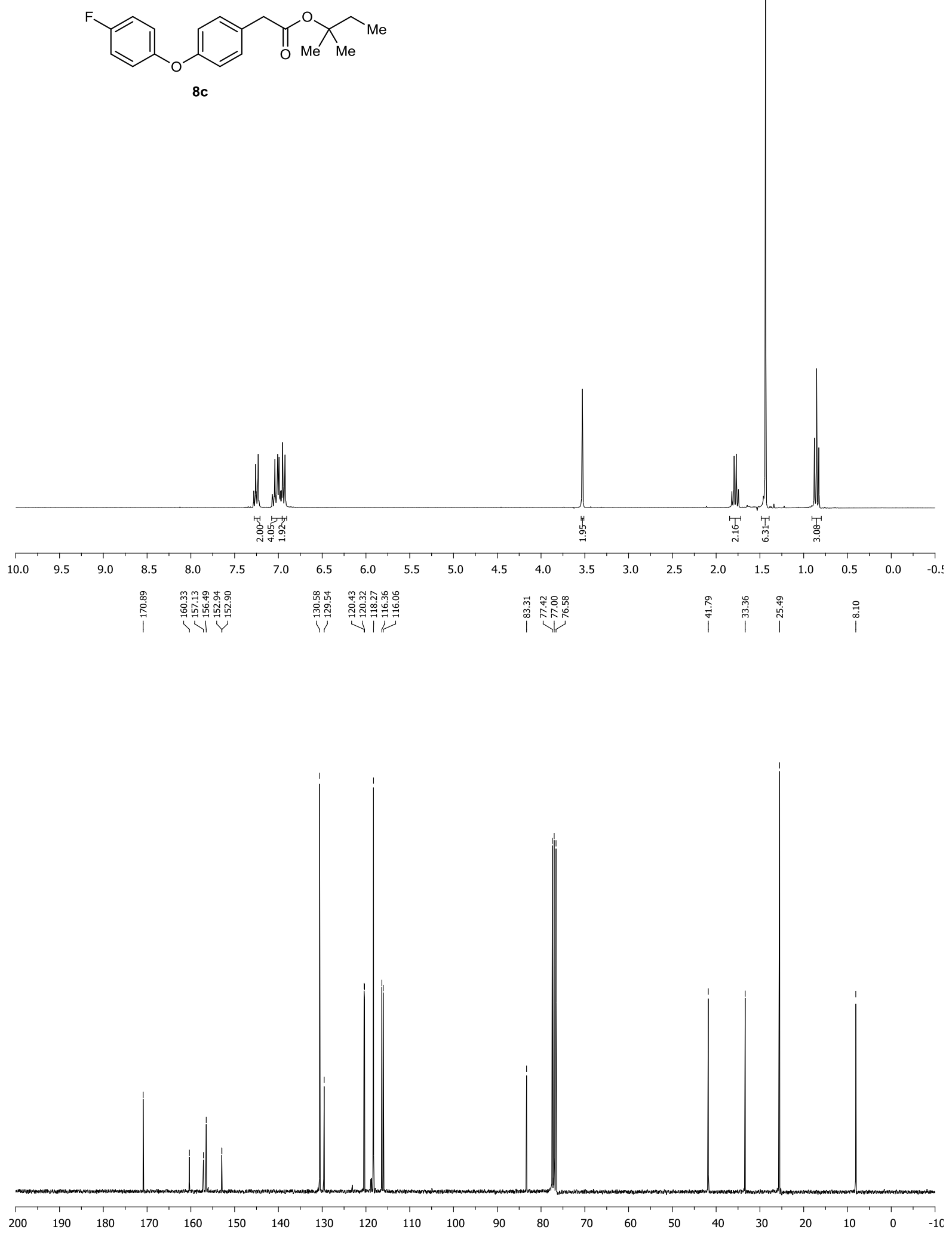
Supporting Information

S32
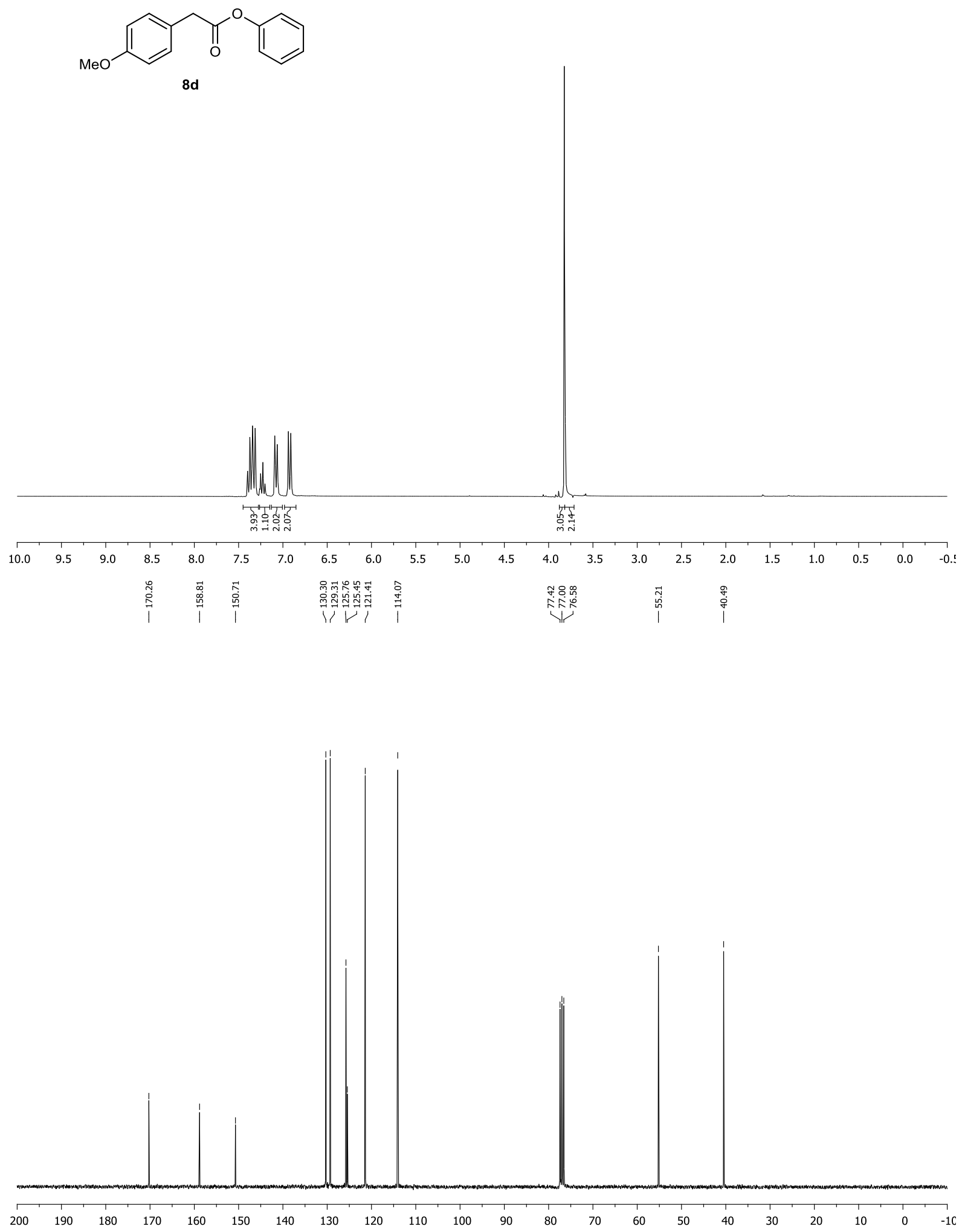

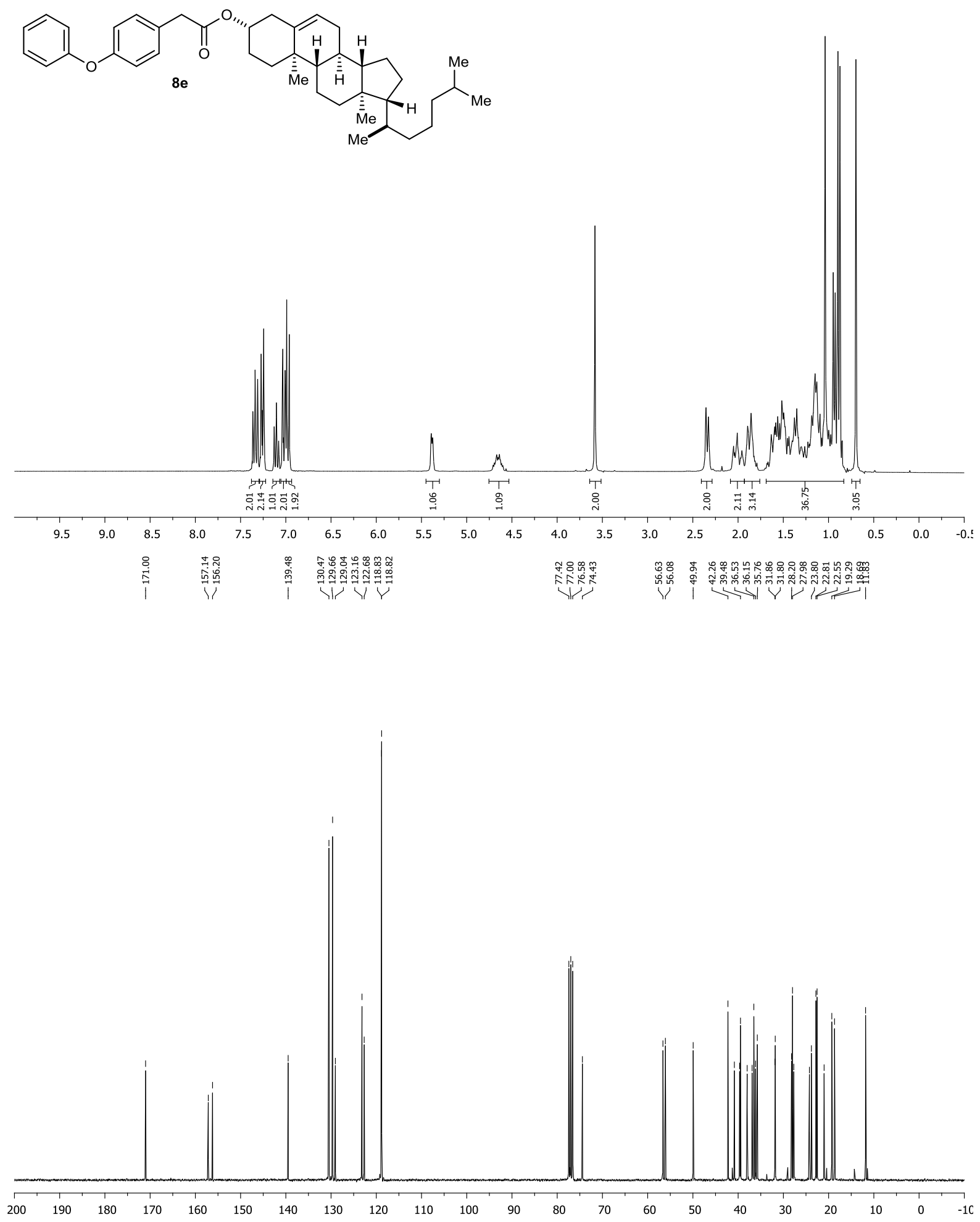
Supporting Information

S34
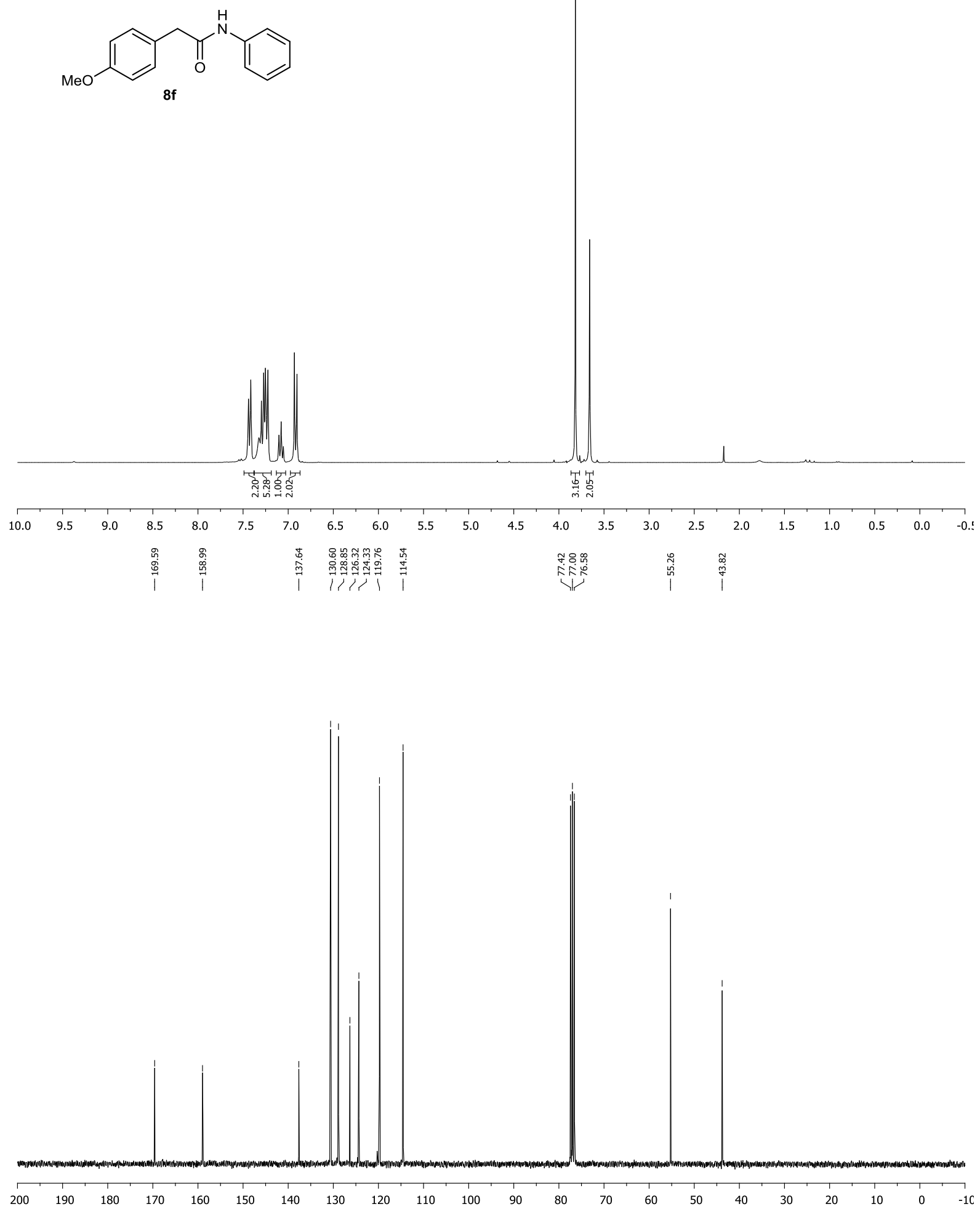
Supporting Information

S35
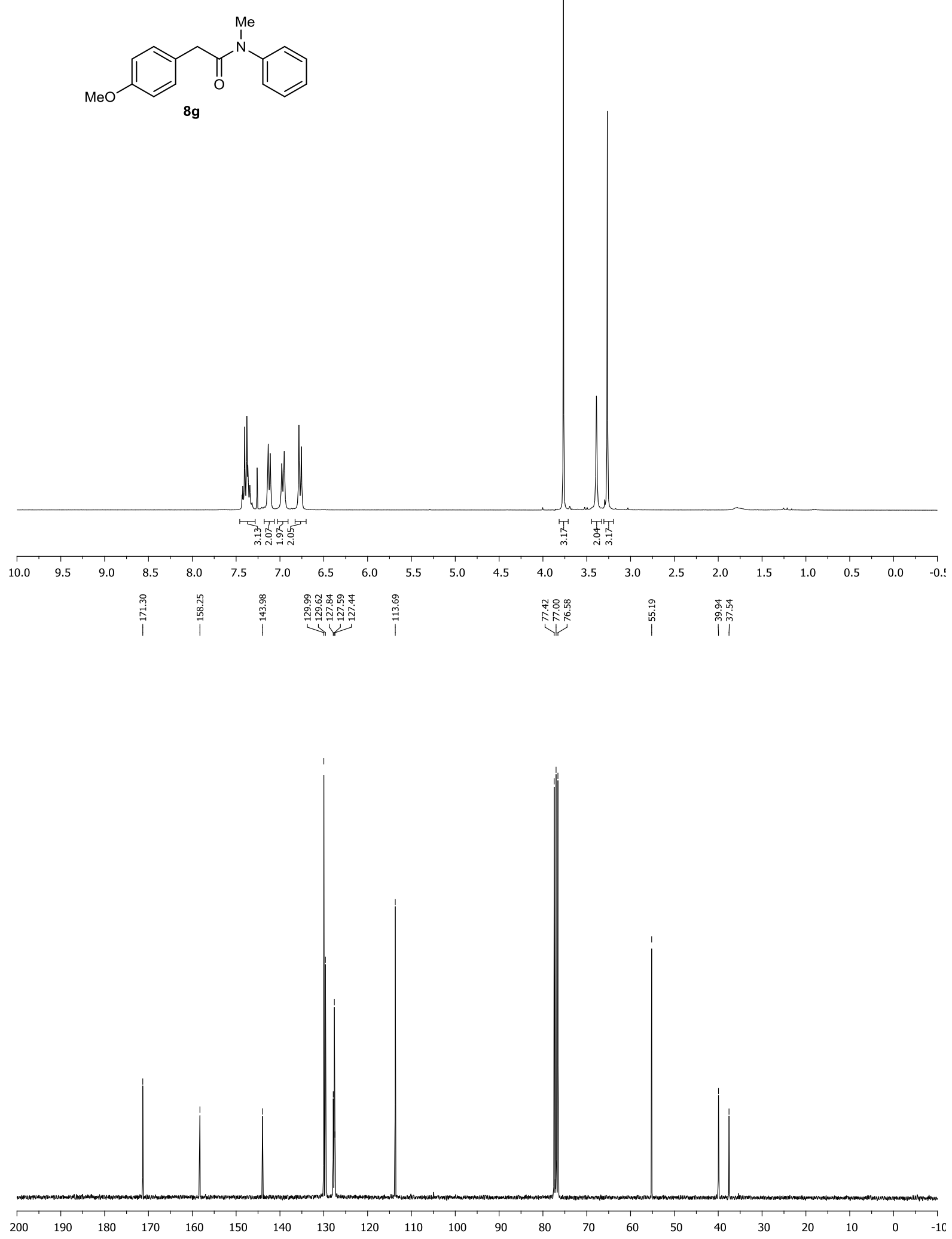

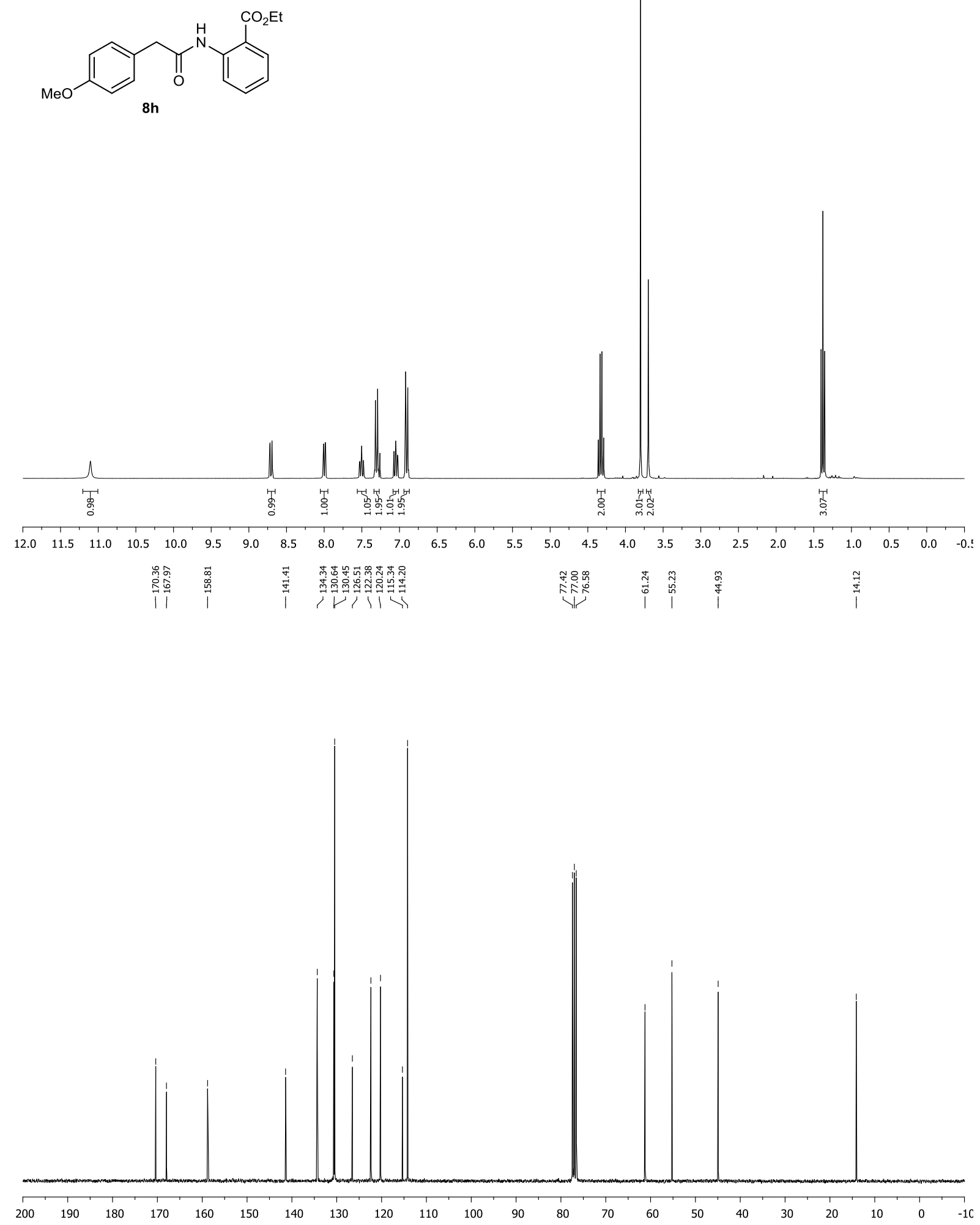

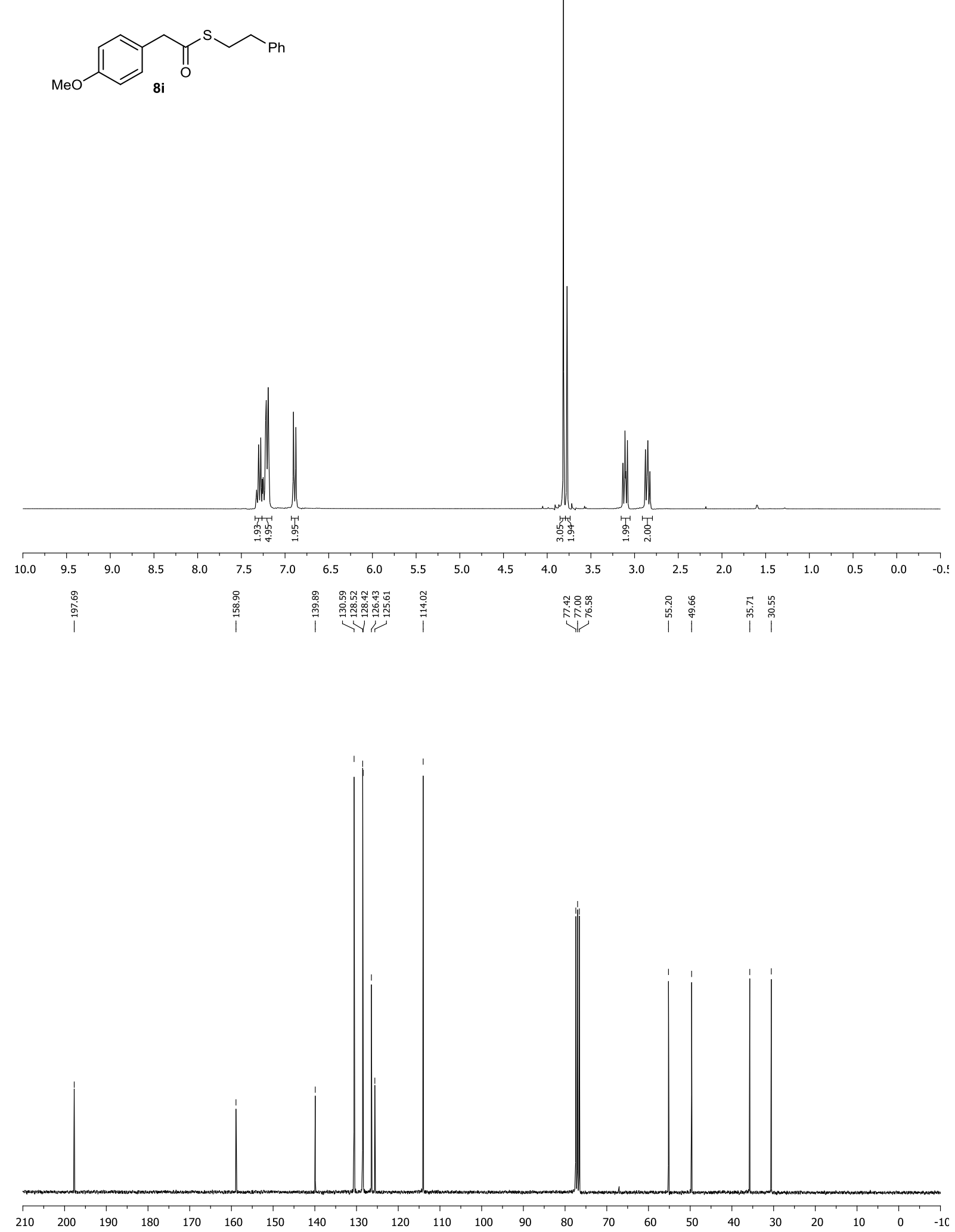

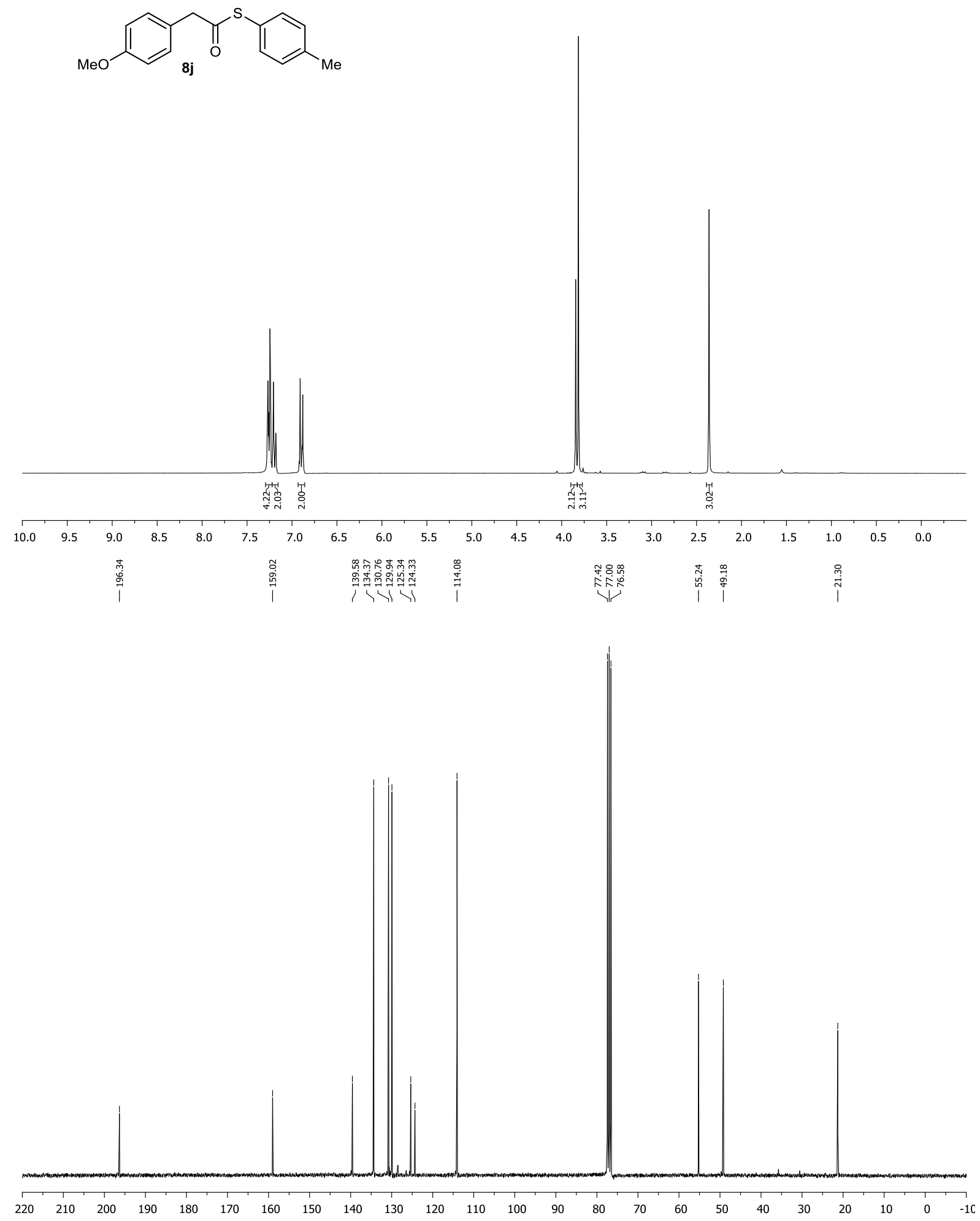
Supporting Information

S39
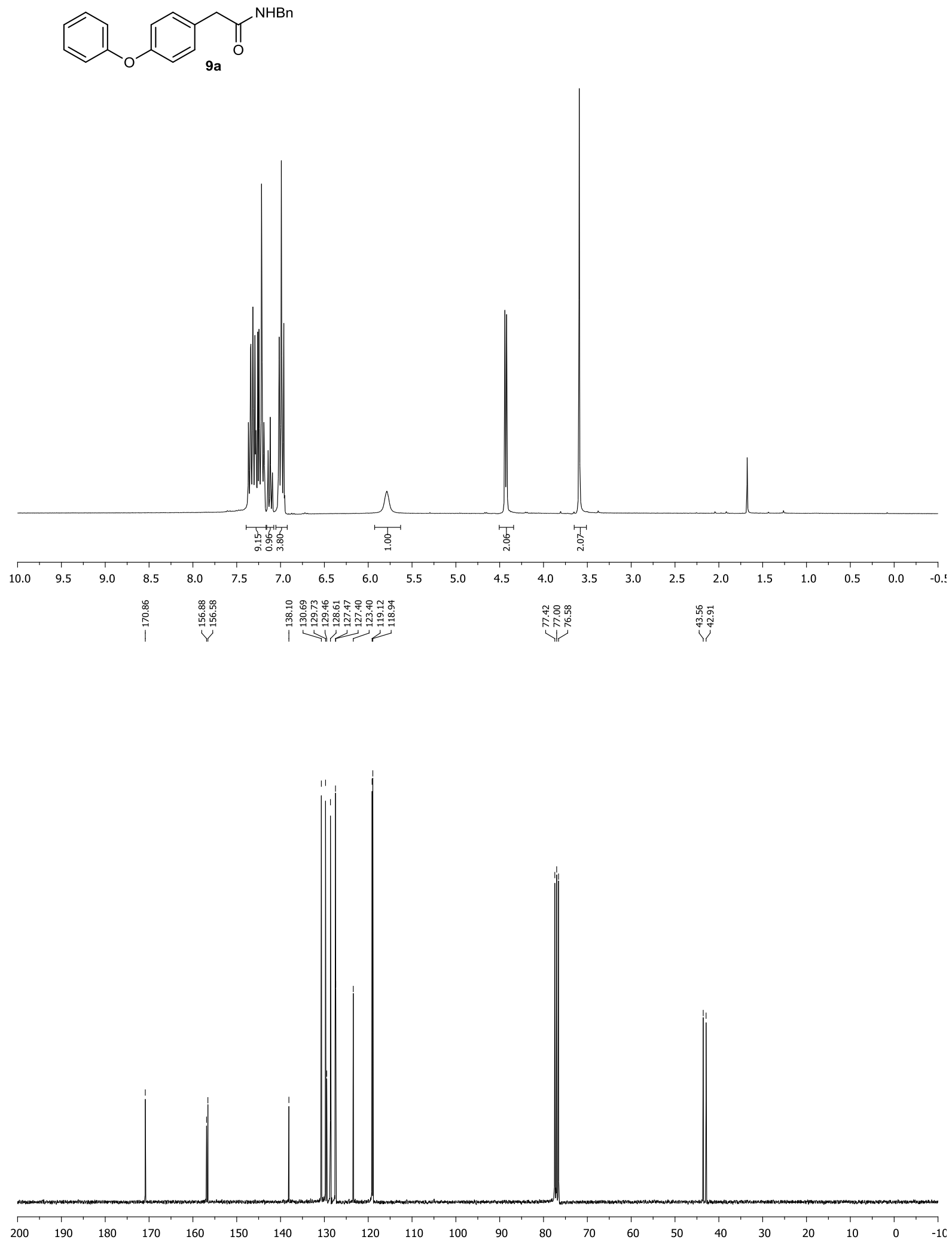


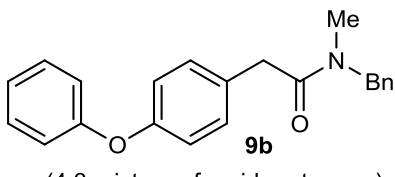

(4:3 mixture of amide rotamers)
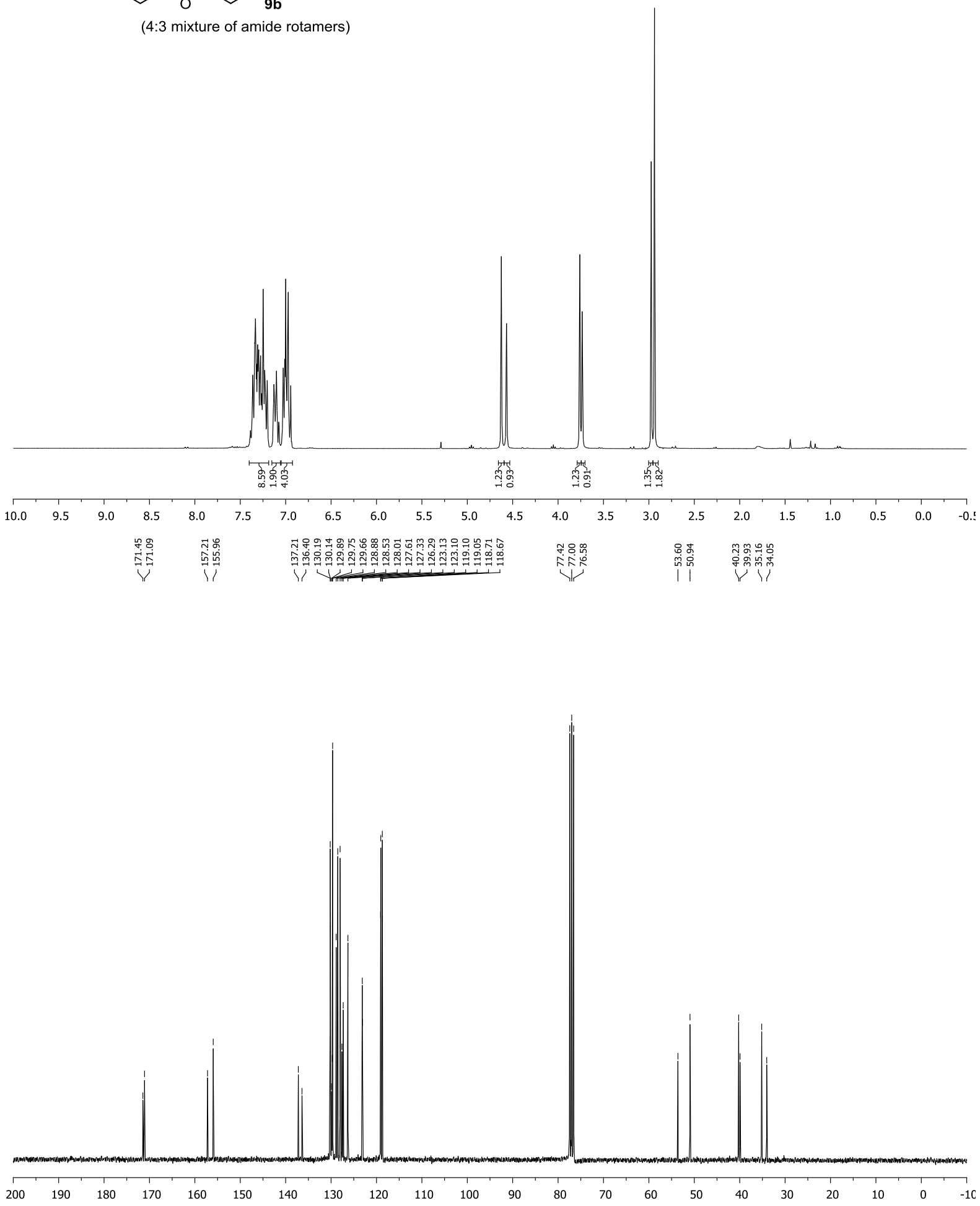

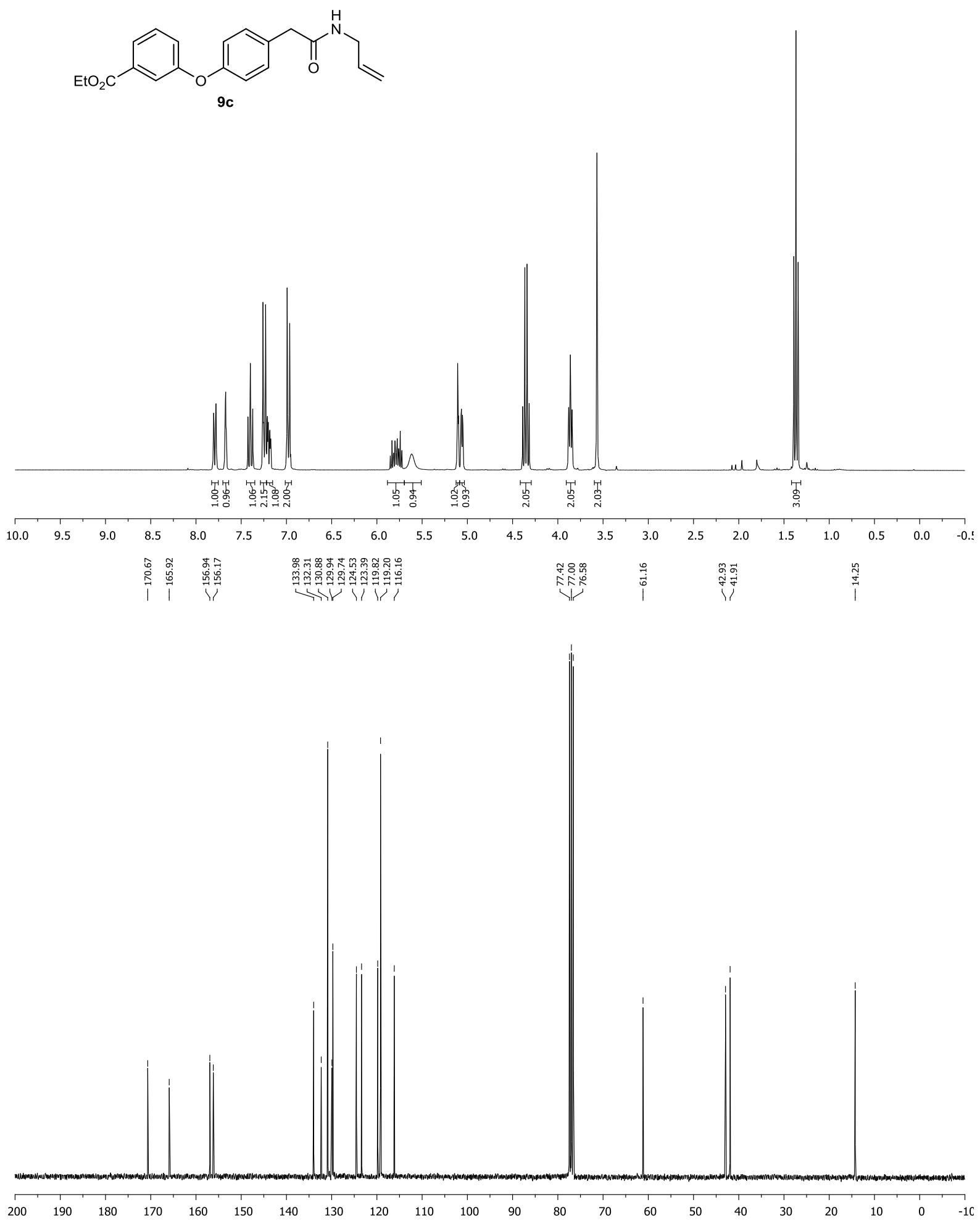
<smiles>CCOC(=O)c1cccc(Oc2ccc(CC(=O)NC(C)(C)C)cc2)c1</smiles>
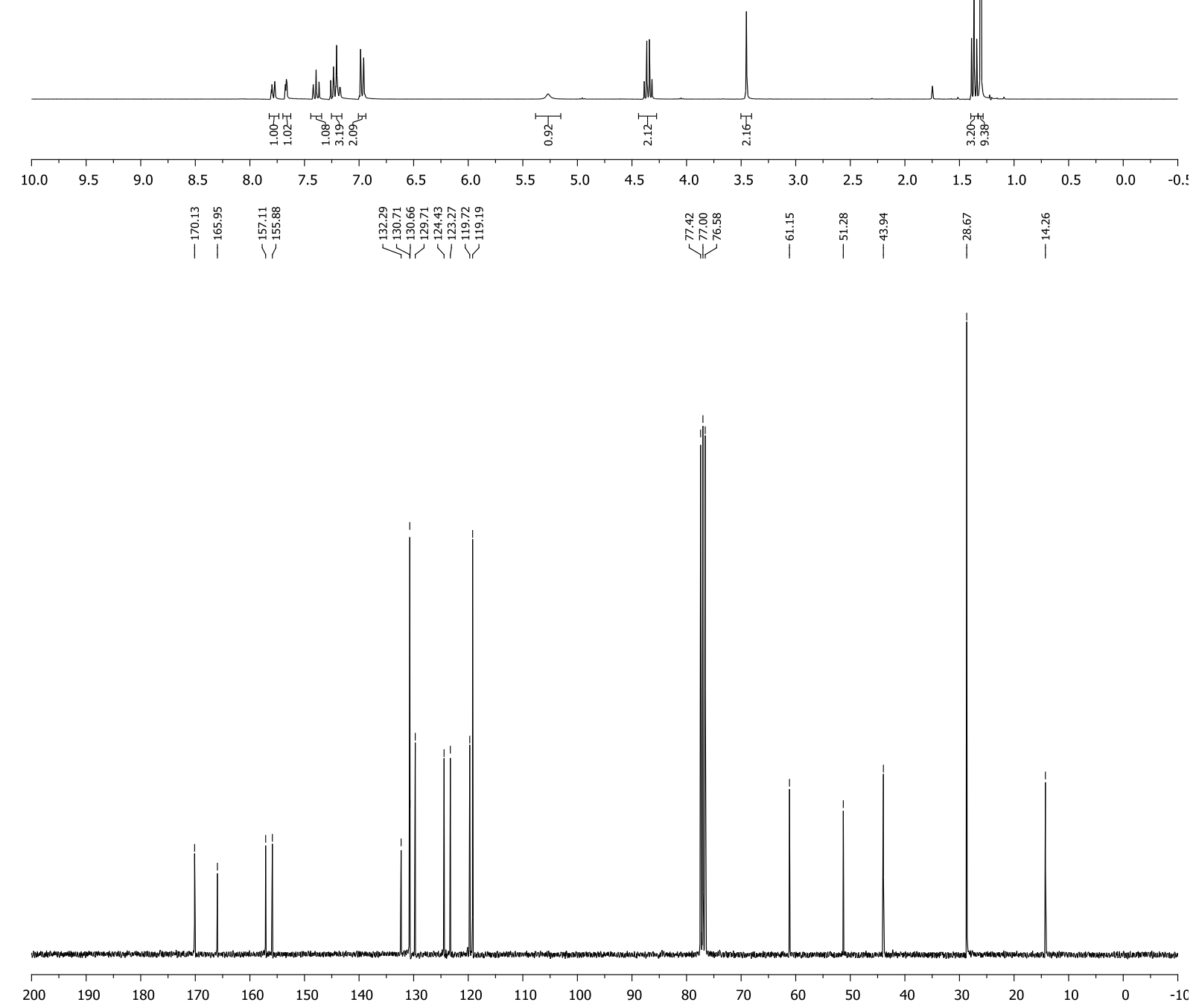
Supporting Information

S43
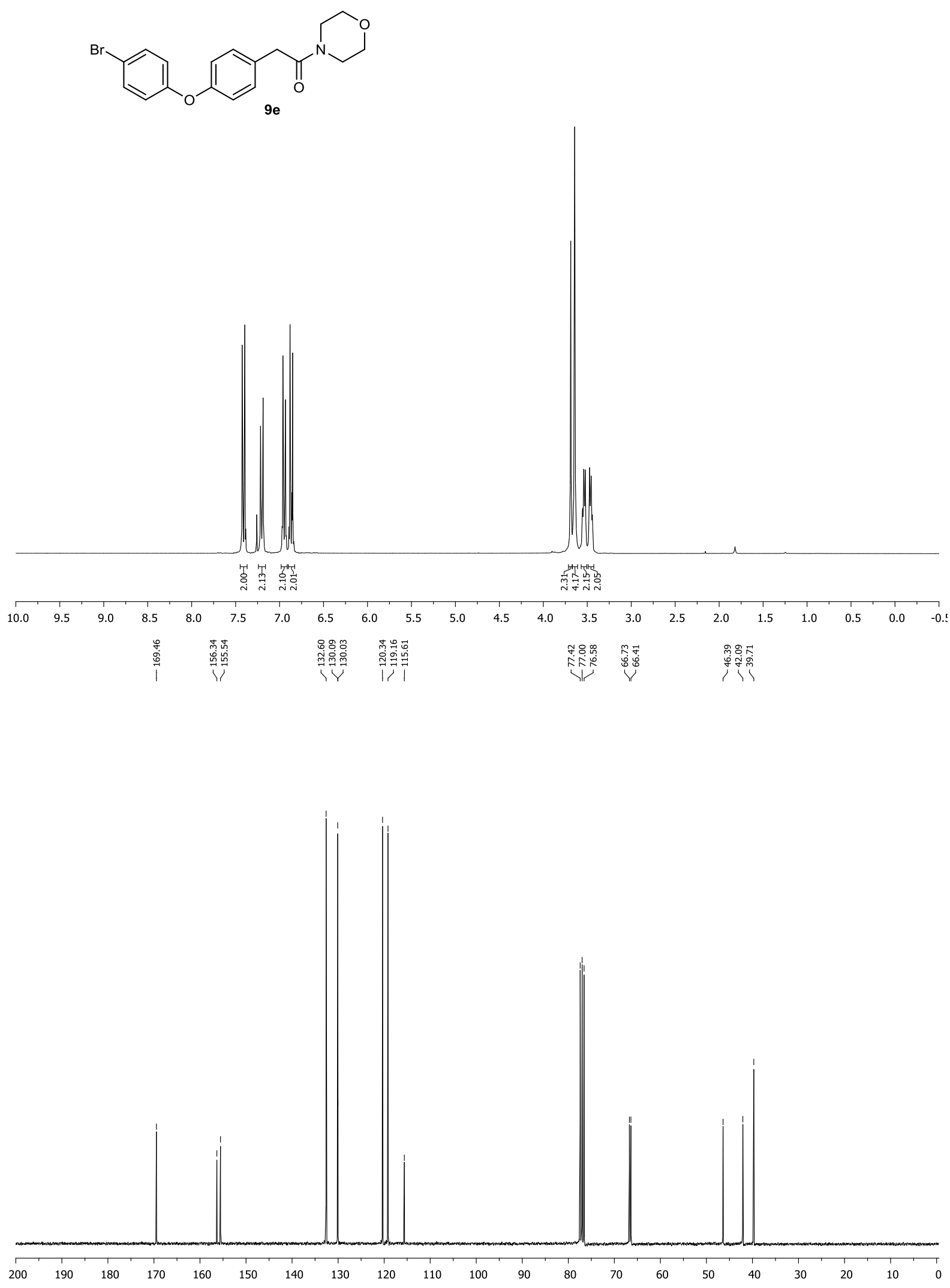


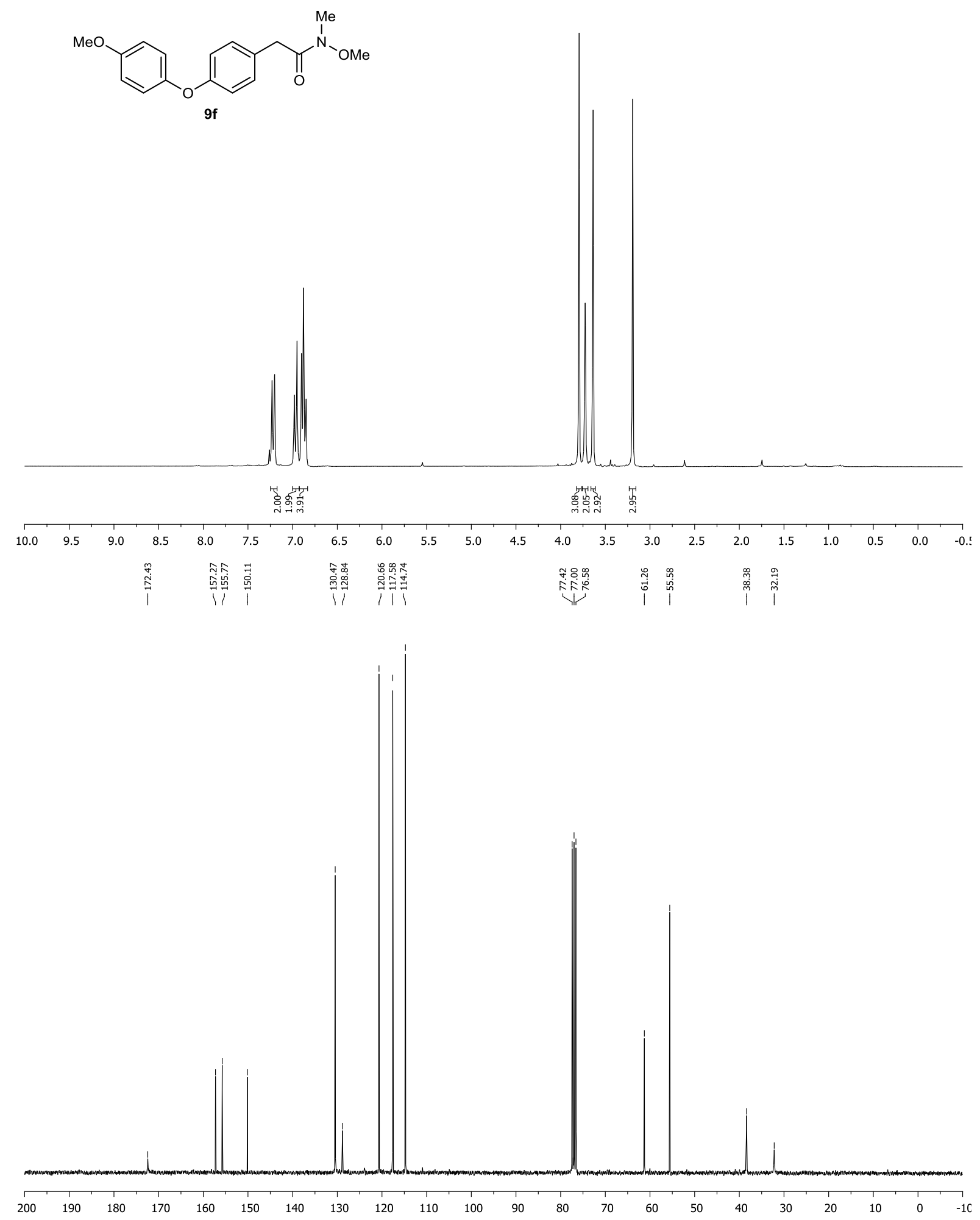


Supporting Information

S45
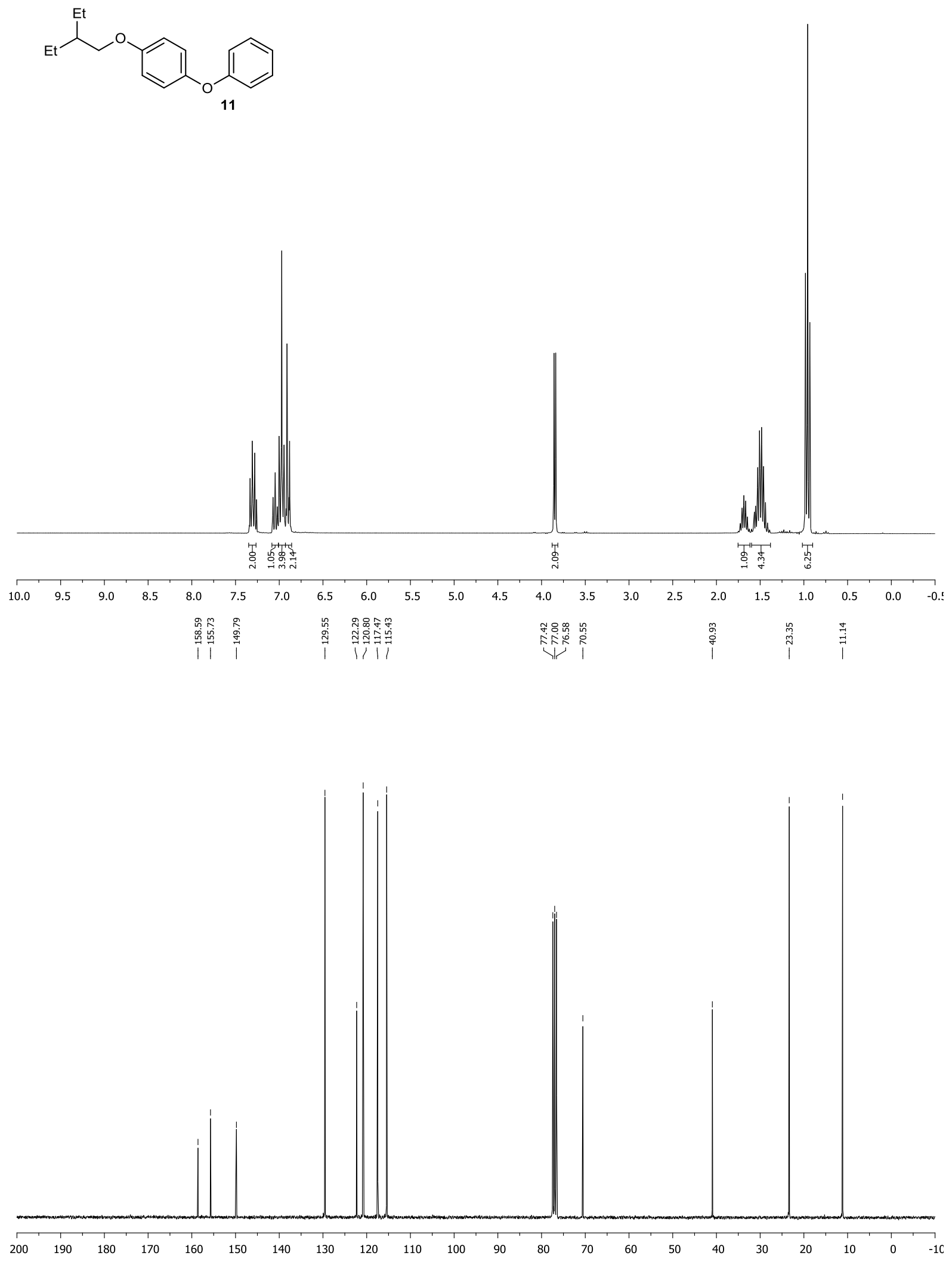
Supporting Information

$S 46$
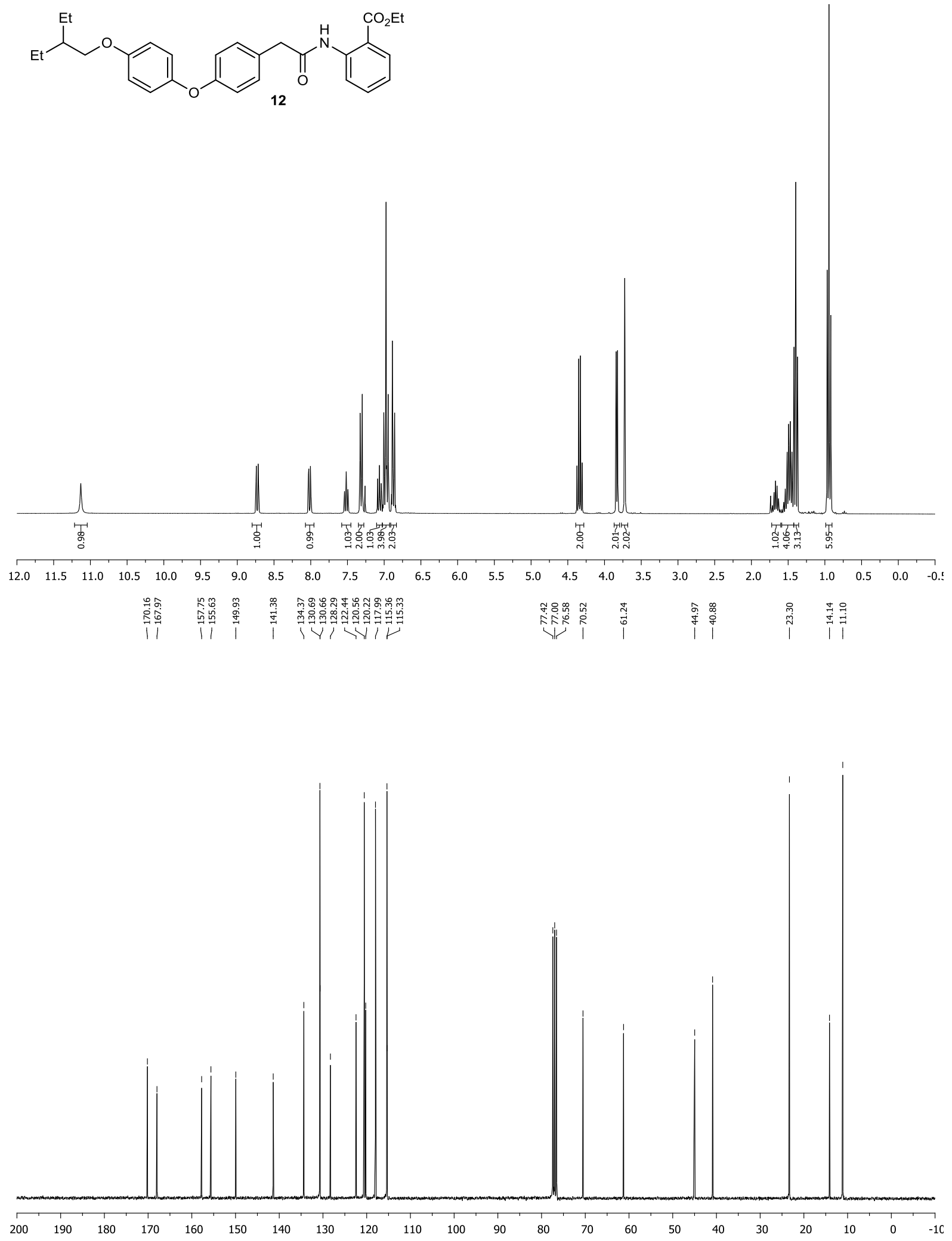
Supporting Information

S47
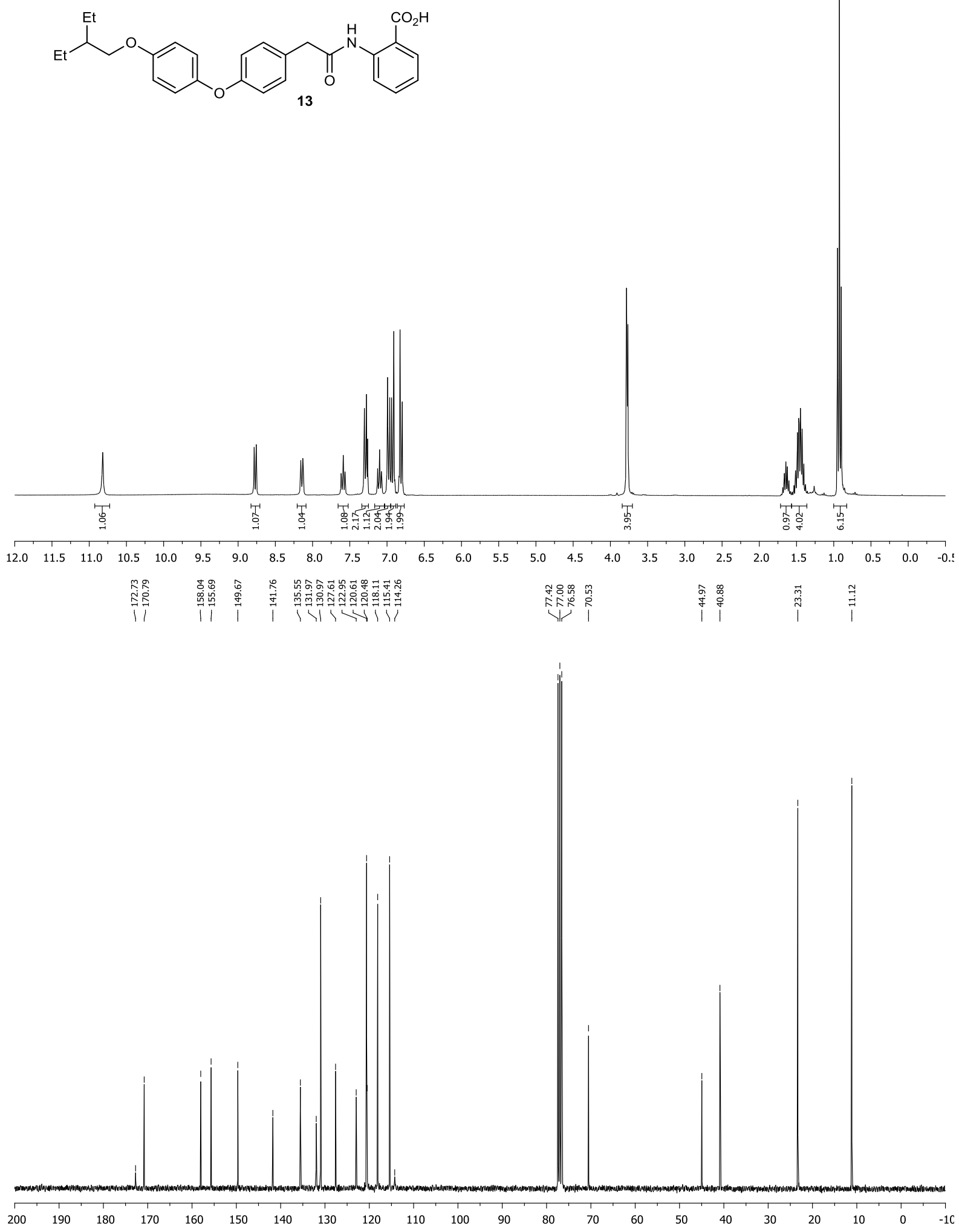